\title{
Review
}

Yuqin Zhang, Gonghua Wu, Shirui Chen, Xu Ju, Wumitijiang Yimaer, Wangjian Zhang, Shao Lin, Yuantao $\mathrm{Hao}^{\star}$, Jing $\mathrm{Gu}^{\star}$ and Jinghua $\mathrm{Li}^{*}$

\section{A review on COVID-19 transmission, epidemiological features, prevention and vaccination}

https://doi.org/10.1515/mr-2021-0023

Received August 30, 2021; accepted December 13, 2021;

published online March 2, 2022

\begin{abstract}
Severe acute respiratory syndrome coronavirus 2 (SARS-CoV-2) has caused hundreds of millions of infections and millions of deaths over past two years. Currently, many countries have still not been able to take the pandemic under control. In this review, we systematically summarized what we have done to mitigate the COVID-19 pandemic, from the perspectives of virus transmission, public health control measures, to the development and vaccination of COVID-19 vaccines. As a virus most likely coming from bats, the SARS-CoV-2 may transmit among people via airborne, faecal-oral, vertical or foodborne routes. Our meta-analysis suggested that the $\mathrm{R}_{0}$ of COVID-19 was 2.9 (95\% CI: 2.7-3.1), and the estimates in Africa and Europe could be higher. The median $R_{t}$ could decrease by $23-96 \%$ following the nonpharmacological interventions, including lockdown, isolation, social distance, and face mask, etc. Comprehensive intervention and lockdown were the most effective measures to control the
\end{abstract}

Yuqin Zhang, and Gonghua Wu, contributed equally to this work.

*Corresponding authors: Yuantao Hao, School of Public Health, Sun Yat-Sen University, Guangzhou, 510080 China; Sun Yat-Sen University Global Health Institute, School of Public Health and Institute of State Governance, Sun Yat-Sen University, Guangzhou, 510080, China, E-mail: haoyt@mail.sysu.edu.cn; Jing Gu and Jinghua Li, School of Public Health, Sun Yat-Sen University, Guangzhou, 510080 China, E-mail: gujing5@mail.sysu.edu.cn (J.Gu),

lijinghua3@mail.sysu.edu.cn (J. Li)

Yuqin Zhang, Gonghua Wu, Shirui Chen, Xu Ju, Wumitijiang Yimaer and Wangjian Zhang, School of Public Health, Sun Yat-Sen University, Guangzhou, China. https://orcid.org/0000-0003-3167-9848

(Y. Zhang)

Shao Lin, Department of Environmental Health Sciences, School of Public Health, University at Albany, State University of New York, Rensselaer, NY, USA pandemic. According to the pooled $\mathrm{R}_{0}$ in our meta-analysis, there should be at least 93.3\% (95\% CI: 89.9-96.2\%) people being vaccinated around the world. Limited amount of vaccines and the inequity issues in vaccine allocation call for more international cooperation to achieve the antiepidemic goals and vaccination fairness.

Keywords: coronavirus; COVID-19; pandemic; review; SARS-CoV-2.

\section{Introduction}

Three major severe epidemics have been reported over the past two decades, including Severe Acute Respiratory Syndrome (SARS), Middle East Respiratory Syndrome (MERS), and the latest severe acute respiratory coronavirus syndrome-2 (SARS-CoV-2), which were all caused by the members of the coronavirus family [1]. Beginning in November 2002, SARS was first identified at the end of February 2003 and quickly spread throughout the world [2]. More than 8000 SARS cases were reported, and the average mortality rate was $11 \%$ [2]. MERS was first reported in Saudi Arabia in September 2012 and 2,494 confirmed cases have been reported in 27 countries till now, with a total of 858 deaths [3, 4] Middle East coronavirus (MERS-CoV) may cause a viral respiratory disease, with symptoms of fever, cough, and shortness of breath. The 2019 novel coronavirus (2019-nCoV), which was later named SARS-CoV-2, was the third coronavirus resulting in a global public health crisis. COVID-19 first emerged at the end of the year 2019 in Wuhan city, Hubei province, China [5]. On 1 February 2020, the World Health Organization (WHO) proclaimed the epidemic as a global emergency [1]. Subsequently, the WHO declared the COVID-19 outbreak a global pandemic on 11 March 2020 [6]. At the time of 12:21 pm CEST, 4 April 2021, the number of global cases of COVID-19 has surpassed 130 million, including 2,839,588 deaths at least [7], more than those killed by SARS and MERS combined. 
Since the outbreak of the disease, a large body of research on SARS-CoV-2 has been done. Estimation of dynamic features has been published under various assumptions to delineate hidden transmissions of the virus [8-10]. While estimates of those important quantities such as the reproduction number have been reported in the literature, those results are quite different and vary considerably across studies. The estimated reproductive number was also found differences across the regions, stages of infection, and the preventive measures applied [11, 12]. Different studies have been carried out on different populations under different conditions, and different authors may make various model assumptions. Since the epidemic began in China, and numerous papers have been published on this issue [9], only a few studies of systematic review and metaanalysis have focused on the basic reproduction number $\left(\mathrm{R}_{0}\right)$ from a global perspective [10,13-15]. In addition, some transmission routes of SARS-CoV-2 have not been clearly determined, and interpretation of the available findings must be coupled with the associated features of the studies.

To address all the issues mentioned above and update our knowledge of COVID-19, in the current review, we aim to provide an overview of COVID-19 transmission, and estimation of reproductive numbers based on worldwide' literature. Moreover, the prevention measures against SARS-CoV-2, the development of vaccines, the vaccination threshold, and the equity issues of vaccination, have also been reviewed and discussed.

\section{SARS-CoV-2}

COVID-19 and SARS have many similar features on transmission and pathogenicity. According to the studies on genome sequencing, SARS-CoV-2 is about $89 \%$ identical to bat SARS-like-CoVZXC21, 82\% identical to human SARS-CoV [16]. However, the novel SARS-CoV-2 virus is spreading much more rapidly compared to the human SARS-CoV. This may be explained by the spike (S) proteins' differences among coronaviruses $[17,18]$. The $S$ protein is one of the structural proteins encoded by the coronavirus genome, and both SARS-CoV-2 and SARS-CoV have the gene that expresses this protein. The spike structure on the virus surface is made by the trimers of S protein [19], and the $\mathrm{S} 1$ functional domain cleaved from the $\mathrm{S}$ protein is responsible for receptor binding. It is shown that the $S$ protein of SARS-CoV-2 can bind with the same receptor of SARS-CoV to invade host cells, that is, angiotensinconverting enzyme 2 (ACE2) [20]. Xu et al. found that the binding free energy for SARS-CoV-2 $\mathrm{S}$ protein to bind with ACE2 is higher compared to SARS-CoV S protein
( -50.6 vs. $-78.6 \mathrm{kcal}$ per mol) because of the loss of hydrogen bond interactions by replacing Arg426 with Asn426 [21]. Wrapp et al. found that the affinity of binding between SARS-CoV-2 and ACE2 is about 10- to 20-fold higher than ACE2 binding to SARS-CoV [22]. Therefore, the stronger binding affinity between SARS-CoV-2 S protein and ACE2 than that between SARS-CoV S protein and ACE2 may partly explain the rapid spreading of COVID-19 [23].

The continual mutations of SARS-CoV-2 have made the situation even more complex. Korber et al. [24] found the S protein amino acid change G614 had become the most prevalent form, which was associated with higher infectiousness. There exist at least three clades characterized by geographic and genomic specificity [25], which represent the different abilities of human-to-human transmission. They found the major prevalent genome in North America is GH (mutations in Spike D614G and ORF3a Q57H), whereas the most frequent clades in Europe and South America are GR. It is shown that the mutations of SARS-CoV-2 would make the pandemic varies in areas and in time.

Long time pandemic status has provided conditions for significant virus mutations. As of 30 November, 2021, there were four variants of the virus being announced as variants of concern (VOC), which is clearly associated with increased transmissibility, severity and/or decreased immunity. The first VOC is B.1.351 labelled as Beta by WHO. It was first detected in South Africa in May 2020. It is 50\% more transmissible than the original virus and its ability to evade some vaccines was ascertained [26]. The second VOC is Gamma which was discovered in Brazil in November 2020. It is said that Gamma is 1.7-2.4 times more transmissible than original [27]. Due to the much higher transmissibility, the VOC Gamma had grown rapidly since December 2020, and it was responsible for the deadly second wave of COVID-19 in Brazil [28]. Another VOC dominating in Europe and the US is Delta. Since it was first discovered in October 2020, it has spread more than 100 countries around the world within 10 months. Researchers described it as an "improved" version of the Alpha variant and it was showed that the people infected with this variant had viral loads as much as 1,260 times higher than people infected with wild-type virus [29]. Many countries have fallen back into the epidemic and India is still stuck in the quagmire of the Delta variant. Last but not the least, South Africa reported a new variant B.1.1.529 in 24 November, 2021. Then, WHO designated this variant a variant of concern and named Omicron on 26 November, 2021 [30]. Although its transmissibility and the impact on current vaccines' effectiveness is unclear, the number of new cases has increased rapidly within recent weeks in South Africa, 
and it has been predominantly the Delta variant. Moreover, some researchers suggest that there may be an increased risk of reinfection with Omicron [31]. This means that the government needs to spend more time and money to fight against the pandemic, and the endpoint of COVID-19 will be far beyond our eyesight.

New variants of the virus not only caused the rebound and prolongation of the epidemic, but also brought anxiety and panic. In the war against COVID-19, we have defeated waves of epidemics, but the endless VOCs have also made us so passive. It is understandable that many countries have taken strict non-pharmaceutical interventions (NPIs) since WHO designating Omicron, although the evidence of this new variant on transmissibility, severity of disease and effectiveness of infection is unclear. Long-term pandemic in many countries have facilitated the mutation of the virus, so that vaccine updates can never keep up with the speed of virus mutation. All these situations point to a worrying future, and taking strict NPIs to clear the infected cases in all countries within a short period may be the only way out. The inaccuracy of testing tools also fuels anxiety and fear, reliable and effective diagnostic testing kits are critical and essential against COVID-19, therefore, it should be considered in designing new testing kits to tackle these mutations and help vaccine developments.

\section{Transmission routes of SARS-CoV-2}

\section{Transmission from animal to human}

Coronaviruses (CoVs) belong to the order Nidovirales, family Coronaviridae, subfamily Coronavirinae, which has been identified to circulate in wild mammals and humans [32, 33]. It is most likely that the novel coronavirus SARS-CoV-2 has originated from bats due to its close phylogenetic relationship with beta-genus lineage b bat SARS-CoV [34]. Before spillover and adaptation to humans, coronaviruses most likely spread to intermediate hosts or animal models [34]. Subsequent to this, these intermediate hosts are increasingly vulnerable to co-infection of these coronaviruses, which also increases the chances of reassortment of viruses that lead to the emergence of novel genotypes, SARS-CoV-2 [35, 36]. Consequently, involving some enabling conditions, the COVID-19 with the potential of cross-species transmission 'jump' to humans and cause an outbreak in the wild animal wet markets of Wuhan, China [37], where wild animals of all kinds including bats were on sale. Evidence of the process of SARS-CoV-2 spreading from bats to humans can be found in the study of Wan et al. [34]. Based on the rich knowledge about SARS-CoV and the newly released sequence of COVID-19, Wan et al. found that the sequence of COVID-19 receptor-binding domain (RBD) is similar to that of SARS-CoV, and receptor-binding motif (RBM) of SARS-CoV-2 directly contacts human angiotensin-converting enzyme 2 (ACE2), strongly suggesting that SARS-CoV uses ACE2 as its receptor. In addition, while phylogenetic analysis indicates a bat origin of SARS-CoV-2, SARS-CoV-2 also potentially recognizes ACE2 from a diversity of animal species, implicating these animal species as possible intermediate hosts or animal models for COVID-19 infections [34].

\section{Transmission from human to human}

\section{Airborne transmission}

The COVID-19 transmission has been confirmed to occur during close person-to-person contact, via respiratory droplets ( $>5-10 \mu \mathrm{m}$ in diameter) and fomites from coughing or sneezing, similar to the transmission modes of SARS and MERS [38]. A study recently performed by Lelieveld et al. [39] estimated the infection risk for different indoor environments such as an office, a classroom, choir practice, and a reception/party. It showed that aerosols from super infective subjects (the top 5-10\% of subjects with a positive test) can effectively cause COVID-19 clusters ( $>10$ infections) in indoor environments [39].

As a direct dispersion of the SARS-CoV-2, microscopic aerosol particles $(<5-10 \mu \mathrm{m}$ in diameter) consisting of the evaporated respiratory droplets can remain airborne for $3 \mathrm{~h}$, and the airborne transportation distance can reach $7-8 \mathrm{~m}[40,41]$. Si et al. investigated the behavior and fate of respiratory droplets $(0.1-4 \mu \mathrm{m}$ in diameter) during coughs in a single-path respiratory tract model. $2 \mu \mathrm{m}$ droplets have the highest exhalation fraction from the pulmonary alveoli. The highest velocity of the exhaled droplets can reach $50 \mathrm{~m} / \mathrm{s}$ for individual droplets [42]. Microscopic aerosol particles can be inhaled and penetrate deeply into the alveolar region of the lungs, readily causing COVID-19 infections in the indoor environment [39].

Alternatively, SARS-CoV-2 may combine with ambient aerosols and enter the human body. There are two possible mechanisms of ambient aerosols on the transmission of COVID-19 [41]. Firstly, ambient aerosols can be the carrier of COVID-19 to enter the human body. Secondly, the ambient aerosol can stimulate the expression of the SARS-CoV-2 receptor to accelerate the infection efficiency [41]. 


\section{Faecal-oral transmission}

Multiple studies highlight the threat of potential faecaloral viral transmission of COVID-19 [43, 44]. In a recent study by Zuo et al. [43], faecal samples of 15 hospitalized patients with COVID-19 were collected, and it was found that 7 of 15 patients had stool positivity for SARS-CoV-2 by RNA shotgun metagenomics sequencing. The faecal viral metagenome of three patients continued to display active viral infection signature up to 6 days after clearance of SARS-CoV-2 from respiratory samples [43]. In addition, faecal samples with a signature of high SARSCoV-2 infectivity harbored a higher abundance of opportunistic pathogens, but live viruses were not to be able to be titrated or isolated from the faeces due to the methodological limitation [43]. A retrospective cohort study collected 3,497 respiratory, stool, serum, and urine samples from 19 January 2020 to 20 March 2020, to evaluate viral loads at different stages of disease progression in patients infected with SARS-CoV-2 in Zhejiang province, China [44]. RNA was detected in the stool of 55 (59\%) patients and the serum of $39(41 \%)$ patients. The urine sample from one patient was positive for SARS-CoV-2 [44]. Xing et al. [45] collected three pediatric cases of COVID-19 reported from January 17, 2020 to February 23, 2020 for Real-time fluorescence reverse-transcriptase-polymerase-chain reaction (RT-PCR) to detect SARS-CoV-2 RNA in throat swabs and fecal specimens. Viral RNA remained positive in the stools of pediatric patients after clearance of SARS-CoV-2 in the respiratory tract [45]. Two children had fecal SARS-CoV-2 turned negative 20 days after throat swabs showing negative, while that of another child lagged for 8 days [45]. These results suggested the potential for the virus to be transmitted through fecal excretion as well. As some studies reported to have prolonged viral RNA in rectal faecal samples [45, 46] more evidence is clearly required to accurately reveal the infectivity and pathogenesis of faecal-oral transmission of SARS-CoV-2 [43, 47].

\section{Vertical transmission}

Vertical transmission is defined as the transmission of the infectious pathogen from the mother to the fetus during the antepartum and intrapartum periods, or to the neonate during the postpartum period via the placenta in utero, body fluid contact during childbirth, or through direct contact owing to breastfeeding after birth [48]. There is limited but increasing evidence of SARS-CoV-2 infection during pregnancy. Several papers report the detection of SARS-CoV-2 RNA in pregnant women who received a coronavirus disease 2019 diagnosis [49-51]. A systematic review and meta-analysis of such studies found that a pooled proportion of $3.2 \%$ of neonates from mothers with COVID-19 have a positive result for severe acute respiratory syndrome coronavirus 2 viral RNA test using a nasopharyngeal swab. Severe acute respiratory syndrome coronavirus 2 viral RNA testing was positive in $2.9 \%$ of neonatal cord blood samples, and $7.7 \%$ of placenta samples [48]. Another systematic review on the possible transmission of SARS-CoV-2 through breast milk and breastfeeding found that break milk samples from $44.0 \%$ of the mothers diagnosed with COVID-19 were reported to be positive for SARS-CoV-2 RNA via RT-PCR analysis [52]. But among the cases with viral RNA detected in breast milk samples, one healthy neonate was fed with a breast milk substitute, while the maternal breast milk samples had detectable viral RNA and thus, it is not possible to ascertain the risk of infection by exposure to breast milk [51]. Given that most neonates born to mothers diagnosed with COVID-19 by RT-PCR tests during their pregnancy were negative for viral infection, and the majority of included studies did not assess the presence of SARS-CoV-2 specific antibodies in neonates, breast milk, placenta, or other tissues and hence, the evidence of possible SARS-CoV-2 transmission through breast milk is still limited [52]. Studies are needed with longer follow-up periods that collect data on infant feeding practices and viral presence in breast milk.

\section{Foodborne transmission}

Although there is no direct proof that SARS-CoV-2 can be transmitted through food consumption [53, 54], concerns have been raised about the link between COVID-19 and contaminated frozen foods [53, 55, 56]. Han et al. [55] reviewed the literature on the persistence of SARS-CoV-2 on food surfaces and possible contamination of foods via the "farm-to-table" lifecycle, including the "cold chain", to provide risk assessments on the foodborne transmission of COVID-19 and other human respiratory pathogens during pandemics. There have been a number of clustered outbreaks reported in food processing facilities since the onset of COVID-19. During April-May 2020, the US Centers for Disease Control and Prevention (CDC) identified 16,233 cases of COVID-19, including 86 deaths, among the workers at 239 meat and poultry processing facilities located in 23 states [57]. Food transmission evidence has been disclosed in China in early July 2020 by the detection of SARS-CoV-2 on frozen foods, including their packaging materials and storage environments, with two re-emergent outbreaks linked to contaminated food sources [55]. Recent studies found that SARS-CoV-2 remained highly stable on both 
refrigerated $\left(4^{\circ} \mathrm{C}\right)$ and freezing $\left(-20^{\circ} \mathrm{C}\right.$ and $\left.-80{ }^{\circ} \mathrm{C}\right)$ foods for 14-21 days [58, 59], and SARS-CoV-2 may be introduced by contaminated cold-chain food sources via food imports [53]. It is necessary to adopt precautionary control measures on food contamination such as enhanced hand and respiratory hygiene, frequent disinfection of hightouch surfaces, isolation of infected workers and their contacts, as well as enhanced screening protocols for international seafood trade [53], otherwise a systematic risk for international spread of SARS-CoV-2 may occur [55].

\section{Epidemiological dynamics of SARS-CoV-2}

\section{Reproduction number $\left(\boldsymbol{R}_{\mathbf{0}}\right)$}

Since the COVID-19 pandemic, a large number of epidemiological and mathematical modeling studies have focused on its transmission characteristics. An important concept in infectious disease research, the basic reproduction number $\left(\mathrm{R}_{0}\right)$, has also been a hotspot. $\mathrm{R}_{0}$ also called the basic reproduction ratio or rate or the basic reproductive rate is a fundamental epidemiologic metric used to assess the contagiousness or transmissibility of infectious agents. The calculation of $R_{0}$ is essential for implementing preventive measures as well $[60,61]$. This index describes the expected number of infections generated by 1 case in a susceptible population. Typically, If $R_{0}$ $<1$, the disease is controlled or not spreading too quickly. If $\mathrm{R}_{0}$ is 1 , then 1 person is capable of spreading to 1 other person on average. If the $R_{0}$ varies between $>1$, the disease can spread to a wider population (exponentially) from one single person, thus potentially creating an epidemic or pandemic [62]. To determine how deadly the COVID-19 is, it is fundamental to evaluate the $R_{0}$ which was frequently referenced during the early stages of the disease [63].

$\mathrm{R}_{0}$ is not constant for a pathogen or a rate over time, and $\mathrm{R}_{0}$ cannot be modified through vaccination campaigns [64]. Although $R_{0}$ is a biological reality, measuring it directly is far from straightforward. Because there are insufficient data collection systems in place to count the number of cases of infection during the early stages of an outbreak to help measure $R_{0}$ most accurately [61]. For instance, in the early stage of SARS-CoV-2, insufficient test kits do not allow every potential patient with COVID-19-like symptoms to be tested, and there has been a good portion of asymptomatic COVID-19 carriers who would never be tested and counted as confirmed cases. As a result, $R_{0}$ is nearly always estimated retrospectively from seroepidemiologic data with complex mathematical models developed using various sets of assumptions [65]. The estimation and interpretation of $R_{0}$ are largely reliant upon understanding contact structure, the estimation method, and model inputs, and epidemiological parameters such as the infectious period and incubation period, which make $R_{0}$ easily misrepresented [61], misinterpreted, and misapplied. Some $R_{0}$ values reported in the scientific literature are likely obsolete. For example, For instance, in a systematic review reporting that the overall $\mathrm{R}_{0}$ was 3.32 (95\% CI: 2.81-3.82), we found control reproduction $\left(\mathrm{R}_{\mathrm{c}}\right)$ numbers or timevarying effective reproduction $\left(R_{t}\right)$ numbers were wrongly extracted from several studies as $R_{0}$ [66-69]. In another review concluding that the estimated mean $\mathrm{R}_{0}$ for COVID-19 is around 3.28, with a median of 2.79 and IQR of 1.16 [60], an $R_{t}$ value was mistaken for $R_{0}[70]$. It is crucial to understand and utilize these metrics cautiously.

\section{A meta-analysis on the $R_{0}$ estimation for COVID-19}

\section{Search strategy and selection criteria}

This systematic review and meta-analysis were conducted to estimate the pooled $\mathrm{R}_{0}$ of COVID-19 in different counties via articles published in international journals. We searched PubMed, Web of Science, bioRxiv, and arXiv to obtain studies published between 1 December 2019 and 21 March 2021 regarding the reproduction number of COVID-19. We used the search terms or combinations of terms as the following - a) "Coronavirus Disease 2019" OR “COVID-19" OR "SARS-CoV-2", b) "model” OR "modeling”, c) "reproductive number". Studies were included if they presented a mathematical/statistical model of SARS-CoV-2 and reported $R_{0}$ and at least one of the following parameters $-R_{t}$, incubation period, generation time, latent period, or serial interval. Studies were excluded if they met the following conditions: a) Studies had conceptual confusion surrounding $R_{0}$ and $R_{t}$, b) Studies did not report necessary parameters like $\mathrm{R}_{0}$ with its $95 \%$ confidence interval (CI), c) Studies with $\mathrm{R}_{\mathrm{t}}$ did not definitely discuss the interventions or the implementing period of the intervention was not reported, d) Simulation studies on $R_{0} / R_{t}$, e) Reviews comments, reports, and letters, f) Articles not in English. Three reviewers (the second author CSR, the third author JX and the fourth author WY) independently performed the literature search and screened titles and abstracts to exclude studies that did not meet our selection criteria before the full review of the full text. Disagreements were resolved by discussion among all authors. 


\section{Data extraction and statistical analysis}

We used a predefined standardized extraction table to extract data. The extracted variables included the name of the first author, area of the study, period of data, model type and settings, estimated $R_{0}$ (with a $95 \%$ confidence interval, CI), estimated $R_{t} / R_{e} / R_{c}$ (with a $95 \%$ confidence interval, $\mathrm{CI}$ ), and public health measures in countries if available. Data extraction was performed by CSR, JX and WY independently, and results were summarized by the cofirst author ZYQ and WGH. Synthesis was carried out to aggregate the information from multiple studies with the same estimates (or effect size of interest) yet different features including the differences in the data collection, the sample size, and the conditions. A meta-analysis was conducted to obtain overall $R_{0}$ and continental $R_{0}$ values.

Heterogeneity between studies was assessed using the Cochran $\mathrm{Q}$ test, the $\mathrm{I}^{2}$ index, and $\mathrm{T}^{2}$ index (Table 1). According to the $\mathrm{I}^{2}$ results, heterogeneity can classified into the following three categories: $\mathrm{I}^{2}<25 \%$ (low heterogeneity), $\mathrm{I}^{2}=25-75 \%$ (average heterogeneity), and $\mathrm{I}^{2}>75 \%$ (high heterogeneity) [71]. Because of the high $\mathrm{I}^{2}$ values that were calculated (99.1\% for the globe, $99.4 \%$ for Asia, $98.4 \%$ for Europe, $90.9 \%$ for Africa, $97.6 \%$ for South America, and $84.1 \%$ for North America), as well as the significance of the Cochran $\mathrm{Q}$ test $(\mathrm{p}<0.0001)$, a random-effects model was used to estimate $R_{0}$ in this work. Publication bias was assessed using Begg and Egger tests, as well as the funnel plots [72]. The bias was adjusted with trim and fill method [73]. Moreover, leave-one-out sensitivity analysis was also employed to assess the robustness of the results. Data were analyzed using R version 3.6.2 [74].

\section{Results of COVID-19 $R_{0}$ estimates}

We identified 1,350 studies, of which 71 were duplicates, which left us with 1,279 reports. A total of 1,039 reports passed the initial title screening, and 718 records were

Table 1: Heterogeneity tests and pooled estimation of the basic reproduction number $\left(R_{0}\right)$ of COVID-19 by region.

\begin{tabular}{lcccrc}
\hline Region & $Q$ & $I^{2}$ & $T^{2}$ & $\begin{array}{r}\text { Pooled } \\
\text { estimate }\end{array}$ & $95 \% \mathrm{Cl}$ \\
\hline Globe & $<0.0001$ & $99.13 \%$ & 0.4415 & 2.88 & $(2.70-3.06)$ \\
Asia & $<0.0001$ & $99.41 \%$ & 0.2866 & 2.39 & $(2.08-2.70)$ \\
Europe & $<0.0001$ & $98.43 \%$ & 0.8076 & 3.15 & $(2.86-3.45)$ \\
Africa & $<0.0001$ & $90.91 \%$ & 0.4302 & 3.06 & $(2.27-3.86)$ \\
South America & $<0.0001$ & $97.63 \%$ & 0.7974 & 2.86 & $(1.77-3.95)$ \\
North America & $<0.0001$ & $84.06 \%$ & 0.4288 & 2.39 & $(1.40-3.38)$ \\
\hline
\end{tabular}

$\mathrm{Cl}$, confidence interval. excluded by abstract, leaving 321 unique studies. Of these, 291 were excluded because they were simulation studies or did not report necessary parameters like $\mathrm{R}_{0}$ with its $95 \%$ confidence interval (CI). 30 publications passed the full-text assessment for eligibility (Figure 1). The 30 included studies with a total of $68 R_{0}$ records used a broad range of methods to generate $R_{0} \cdot 63.3 \%$ (19/30) were compartment models, among which $26.3 \%$ (5/19) and 57.9\% (11/19) of models belong to Susceptible-Infected-Recovered (SIR) models and Susceptible-Exposed-Infectious-Recovered (SEIR) models, respectively. $36.7 \%$ (11/30) of reviewed papers used other kinds of models such as the networked dynamic metapopulation model [75], the generalized growth model (GGM) [76, 77], the extended and modified Flaxman model [78], etc. 30 studies included in the meta-analysis reported estimated $\mathrm{R}_{0}$ and its $95 \% \mathrm{CI}$ (Table 2). All the reports were conducted in 43 countries and regions in 2020, including much of East Asia, South Asia, and Europe, and a handful of countries in Africa and North and South America. The proportion of reviewed records in these five continents were shown in Figure 2.

The median $\mathrm{R}_{0}$ was 2.9 (IQR, 2.1-3.8) for all the reviewed studies. After stratified by continents, median $\mathrm{R}_{0}$ for Asia, Europe, Africa, South America, and North America over the whole outbreak periods were 2.4 (IQR, 2.1-2.6), 3.3 (IQR, 2.4-4.3), 3.2 (IQR, 2.8-3.5), 2.6 (IQR, 2.4-3.1) and 2.4 (IQR, 2.1-2.6), respectively. For publication bias assessment, the funnel plot (see Figure S1, Supplementary material), Begg test $(\mathrm{p}<0.0001)$, and Egger test $(\mathrm{p}=0.0241)$ suggested significant bias. The sensitivity analysis showed that no individual study significantly affected the pooled results of $\mathrm{R}_{0}$ (see Table $\mathrm{S} 1$, Supplementary material, which illustrates the sensitivity analysis results of meta-analysis for $\mathrm{R}_{0}$ estimates). According to the results of the randomeffects model, the pooled $\mathrm{R}_{0}$ for COVID-19 was estimated as 2.9 (95\% CI: 2.7-3.1), which means that each person infected with COVID-19 transmitted the infection to between 2 and three susceptible people on average. After stratified by continents, pooled $\mathrm{R}_{0}$ estimates for Asia, Europe, Africa, South America and North America were 2.4 (95\% CI: 2.1-2.7), 3.2 (95\% CI: 2.9-3.5), 3.1 (95\% CI: 2.3-3.9), 2.9 (95\% CI: 1.8-4.0) and 2.4 (95\% CI: 1.4-3.4), respectively (Table 1). We stratified the analysis by sources of cases to make the $\mathrm{R}_{0}$ values comparable as well. Confirmed cases are people that have been tested, and the test confirms they have COVID-19 (i.e., a positive test). While the reported case figures on a given date do not necessarily show the number of new cases on that day - this is due to delays in reporting. The actual number of cases is likely to be much higher than the number of confirmed cases - this is due to limited testing. Confirmed cases have been 

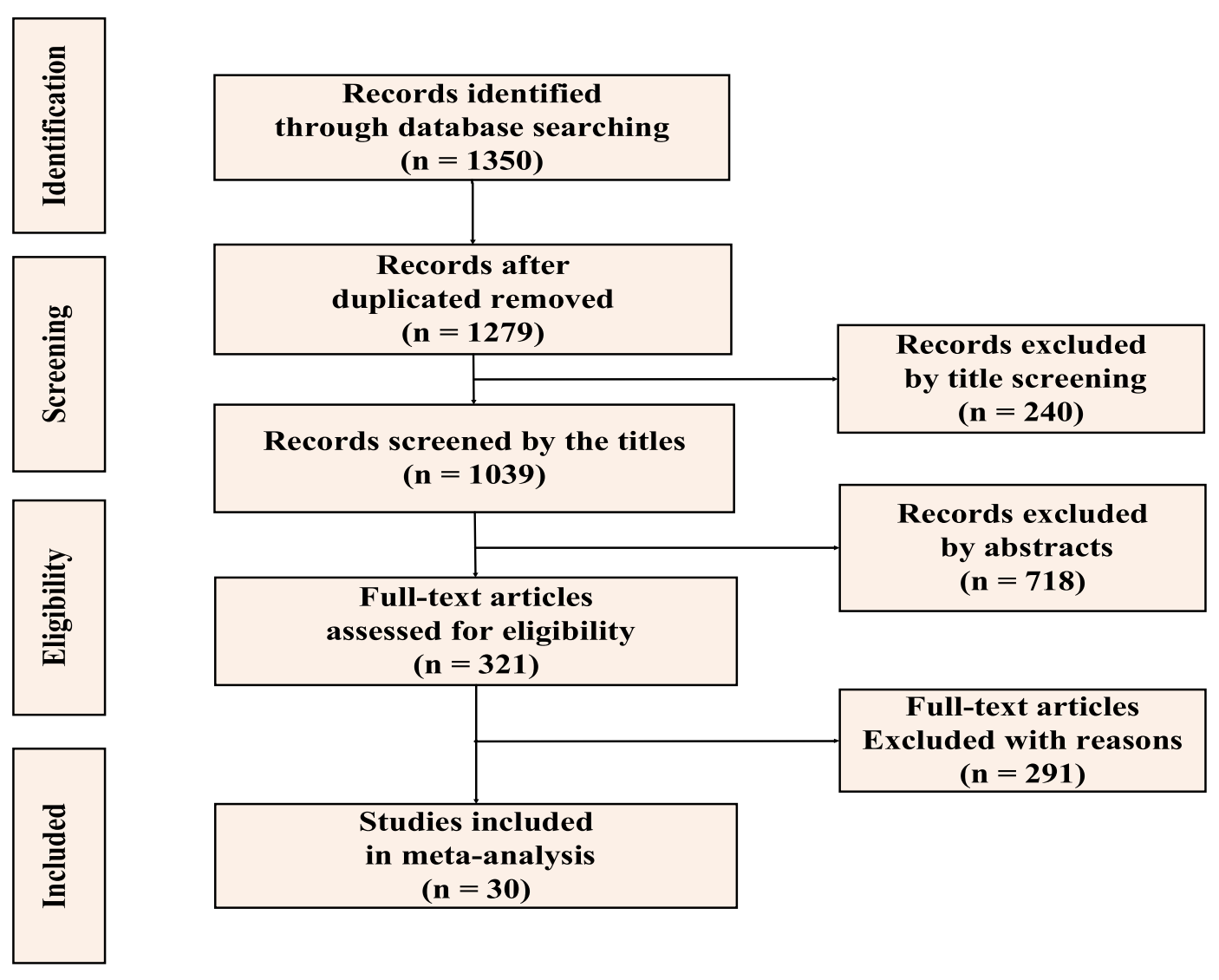

Figure 1: Flowchart of reports selection for inclusion in the systematic review.

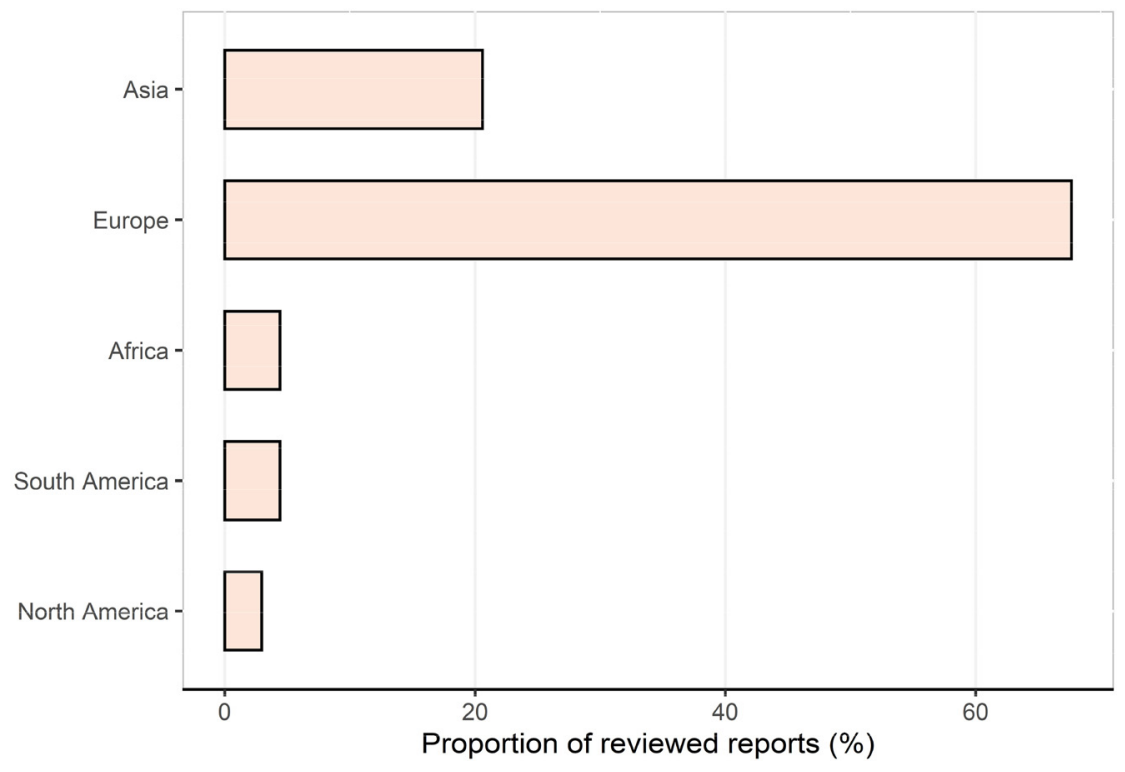

Figure 2: The proportion of records reporting $R_{0}$ values in five continents. $R_{0}$, the basic reproduction number. used for $\mathrm{R}_{0}$ estimates 20 out of the 30 studies (Table 2). As demonstrated in Figure $3 \mathrm{~A}$ and $\mathrm{B}$, the pooled $\mathrm{R}_{0}$ estimate for confirmed cases $\left(\mathrm{R}_{0}, 2.9\right.$; $95 \%$ CI: 2.7-3.1) was higher than that for reported cases $\left(\mathrm{R}_{0}, 2.6\right.$; $95 \%$ CI: 2.3-2.9).
It is necessary to estimate the $R_{0}$ of COVID-19 to determine the capability of transmission per primary infected person to the secondarily infected persons [105], as well as to provide a reference for the government to make 
Table 2: Descriptive characteristics of the records included in the meta-analysis.

\begin{tabular}{|c|c|c|c|c|c|c|}
\hline Study & Study region & Study period & $\mathbf{R}_{\mathbf{0}}$ & LCL & UCL & Sources of cases \\
\hline Adekunle et al. [79] & Nigeria & $2020 / 02 / 27-2020 / 05 / 07$ & 2.42 & 2.37 & 2.47 & Confirmed cases \\
\hline Rouabah et al. [80] & Algeria & $2020 / 02 / 25-2020 / 05 / 24$ & 3.78 & 3.03 & 4.53 & Confirmed cases \\
\hline Talmoudi et al. [81] & Tunisia & $2020 / 02 / 29-2020 / 05 / 05$ & 3.18 & 2.73 & 3.69 & Reported cases \\
\hline Chen Xu et al. [82] & Korea & Data collected about different countries & 1.59 & 1.58 & 1.60 & Confirmed cases \\
\hline
\end{tabular}

Genya Kobayashi et al. [83] Japan

Hao Lei et al. [84]

Mohak Gupta et al. [85]

Muniz-Rodriguez et al. [76]

Muniz-Rodriguez et al. [76]

Quan-Hui Liu et al. [86]

Ruiyun Li et al. [75]

Sardar et al. [87]

Saurabh et al. [88]

Sugishita [89]

Toshikazu Kuniya [90]

Xingjie Hao et al. [91]

Zhang et al. [92]

Damjan Manevski et al. [78]

Jia Wangping et al. [93]

Kevin Linka et al. [94]

Kevin Linka et al. [94]

Kevin Linka et al. [94]

Kevin Linka et al. [94]

Kevin Linka et al. [94]

Kevin Linka et al. [94]

Kevin Linka et al. [94]

Kevin Linka et al. [94]

Kevin Linka et al. [94]

Kevin Linka et al. [94]

Kevin Linka et al. [94]

Kevin Linka et al. [94]

Kevin Linka et al. [94]

Kevin Linka et al. [94]

Kevin Linka et al. [94]

Kevin Linka et al. [94]

Kevin Linka et al. [94]

Kevin Linka et al. [94]

Kevin Linka et al. [94]

Kevin Linka et al. [94]

Kevin Linka et al. [94]

Kevin Linka et al. [94]

Kevin Linka et al. [94]

Kevin Linka et al. [94]

Kevin Linka et al. [94]

Kevin Linka et al. [94]

Kevin Linka et al. [94]

Laura Di Domenico et al. [95]

Lemaitre Joseph et al. [96]

Mamon [97]

Mamon [97]

Seth Flaxman et al. [98]

Seth Flaxman et al. [98]

Seth Flaxman et al. [98]

Seth Flaxman et al. [98]

\begin{tabular}{|c|c|}
\hline Japan & $2020 / 03 / 1-2020 / 04 / 22$ \\
\hline China & $2019 / 12 / 1-2020 / 03 / 11$ \\
\hline India & $2020 / 03 / 04-2020 / 04 / 25$ \\
\hline Iran & $2020 / 02 / 19-2020 / 03 / 19$ \\
\hline Iran & $2020 / 02 / 19-2020 / 03 / 19$ \\
\hline China & $2020 / 01 / 21-2020 / 04 / 19$ \\
\hline China & $2020 / 01 / 10-2020 / 02 / 08$ \\
\hline India & $2020 / 03 / 14-2020 / 05 / 03$ \\
\hline India & $2020 / 03 / 09-2020 / 07 / 06$ \\
\hline Japan & $2020 / 1 / 14-2020 / 03 / 26$ \\
\hline Japan & $2020 / 01 / 15-2020 / 06 / 30$ \\
\hline China & $2019 / 12 / 08-2020 / 03 / 08$ \\
\hline China & $2019 / 12 / 1-2020 / 4 / 21$ \\
\hline Slovenia & $2020 / 03 / 04-2020 / 06 / 03$ \\
\hline Italy & $2020 / 01 / 22-2020 / 04 / 02$ \\
\hline Austria & $2020 / 05 / 10-2020 / 06 / 10$ \\
\hline Belgium & $2020 / 01 / 24-2020 / 06 / 10$ \\
\hline Bulgaria & $2020 / 01 / 24-2020 / 06 / 10$ \\
\hline Croatia & $2020 / 01 / 24-2020 / 06 / 10$ \\
\hline Cyprus & $2020 / 01 / 24-2020 / 06 / 10$ \\
\hline Czech Republic & $2020 / 01 / 24-2020 / 06 / 10$ \\
\hline Denmark & $2020 / 01 / 24-2020 / 06 / 10$ \\
\hline Estonia & $2020 / 01 / 24-2020 / 06 / 10$ \\
\hline Finland & $2020 / 01 / 24-2020 / 06 / 10$ \\
\hline France & $2020 / 01 / 24-2020 / 06 / 10$ \\
\hline Germany & $2020 / 01 / 24-2020 / 06 / 10$ \\
\hline Greece & $2020 / 01 / 24-2020 / 06 / 10$ \\
\hline Hungary & $2020 / 01 / 24-2020 / 06 / 10$ \\
\hline Ireland & $2020 / 01 / 24-2020 / 06 / 10$ \\
\hline Italy & $2020 / 01 / 24-2020 / 06 / 10$ \\
\hline Latvia & $2020 / 01 / 24-2020 / 06 / 10$ \\
\hline Lithuania & $2020 / 01 / 24-2020 / 06 / 10$ \\
\hline Luxembourg & $2020 / 01 / 24-2020 / 06 / 10$ \\
\hline Malta & $2020 / 01 / 24-2020 / 06 / 10$ \\
\hline Netherlands & $2020 / 01 / 24-2020 / 06 / 10$ \\
\hline Poland & $2020 / 01 / 24-2020 / 06 / 10$ \\
\hline Portugal & $2020 / 01 / 24-2020 / 06 / 10$ \\
\hline Romania & $2020 / 01 / 24-2020 / 06 / 10$ \\
\hline Slovakia & $2020 / 01 / 24-2020 / 06 / 10$ \\
\hline Slovenia & $2020 / 01 / 24-2020 / 06 / 10$ \\
\hline Spain & $2020 / 01 / 24-2020 / 06 / 10$ \\
\hline Sweden & $2020 / 01 / 24-2020 / 06 / 10$ \\
\hline France & $2020 / 03 / 01-2020 / 04 / 05$ \\
\hline Switzerland & $2020 / 02 / 24-2020 / 04 / 24$ \\
\hline France & $2020 / 03 / 19-2020 / 05 / 03$ \\
\hline France & $2020 / 03 / 19-2020 / 05 / 03$ \\
\hline Denmark & $2020 / 02-2020 / 05 / 04$ \\
\hline Italy & $2020 / 02-2020 / 05 / 04$ \\
\hline Germany & $2020 / 02-2020 / 05 / 04$ \\
\hline Spain & $2020 / 02-2020 / 05 / 04$ \\
\hline
\end{tabular}

were from the date when the first case in
country was reported to March 23, 2020

1.42

$\begin{array}{lll}2.12 & 2.02 & 2.21\end{array}$

$\begin{array}{lll}2.08 & 2.04 & 2.12\end{array}$

$\begin{array}{lll}3.50 & 1.30 & 8.10\end{array}$

$\begin{array}{lll}4.40 & 3.90 & 4.90\end{array}$

$\begin{array}{lll}2.40 & 1.60 & 3.70\end{array}$

$\begin{array}{lll}2.23 & 1.77 & 3.00\end{array}$

$\begin{array}{lll}2.03 & 1.66 & 2.33\end{array}$

$\begin{array}{lll}1.62 & 1.07 & 2.17\end{array}$

$\begin{array}{lll}2.53 & 2.45 & 2.60\end{array}$

$\begin{array}{lll}2.60 & 2.40 & 2.80\end{array}$

$\begin{array}{lll}3.54 & 3.40 & 3.67\end{array}$

$\begin{array}{lll}2.33 & 1.96 & 3.69\end{array}$

$\begin{array}{lll}3.90 & 1.56 & 9.68\end{array}$

$\begin{array}{lll}4.34 & 3.04 & 6.00\end{array}$

$\begin{array}{llll}4.22 & 1.08 \quad 7.36\end{array}$

$\begin{array}{lll}4.30 & 3.59 & 5.01\end{array}$

$\begin{array}{lll}5.00 & 3.57 & 6.43\end{array}$

$\begin{array}{lll}1.29 & 1.21 & 1.37\end{array}$

$\begin{array}{lll}0.93 & 0.50 & 1.36\end{array}$

$\begin{array}{lll}0.35 & 1.12 & 5.58\end{array}$

$\begin{array}{lll}2.92 & 2.00 & 3.84\end{array}$

$\begin{array}{lll}2.00 & 1.90 & 2.10\end{array}$

$\begin{array}{lll}3.12 & 1.59 & 4.65\end{array}$

$\begin{array}{lll}1.62 & 1.52 & 1.72\end{array}$

$\begin{array}{lll}3.46 & 2.89 & 4.03\end{array}$

$\begin{array}{lll}6.33 & 5.08 & 7.58\end{array}$

$\begin{array}{lll}1.66 & 1.42 & 1.90\end{array}$

$\begin{array}{lll}1.97 & 0.89 & 3.05\end{array}$

$\begin{array}{lll}1.94 & 1.82 & 2.06\end{array}$

$\begin{array}{lll}4.25 & 3.43 & 5.07\end{array}$

$\begin{array}{lll}2.50 & 0.76 & 4.24\end{array}$

$\begin{array}{lll}0.91 & -0.81 & 2.63\end{array}$

$\begin{array}{lll}2.42 & 0.05 & 4.79\end{array}$

$\begin{array}{lll}2.08 & 1.81 & 2.35\end{array}$

$\begin{array}{lll}5.88 & 4.16 & 7.60\end{array}$

$\begin{array}{lll}2.62 & 2.11 & 3.13\end{array}$

$\begin{array}{lll}5.10 & 3.41 & 6.79\end{array}$

$\begin{array}{lll}6.06 & 4.41 & 7.71\end{array}$

$\begin{array}{lll}1.46 & 1.38 & 1.54\end{array}$

$\begin{array}{lll}3.83 & 1.95 & 5.71\end{array}$

$\begin{array}{lll}5.19 & 4.21 & 6.17\end{array}$

$\begin{array}{lll}3.18 & 3.09 & 3.24\end{array}$

$\begin{array}{lll}2.80 & 2.10 & 3.80\end{array}$

$\begin{array}{lll}2.84 & 2.65 & 3.10\end{array}$

$3.43 \quad 3.31-3.51$

$\begin{array}{lll}3.55 & 2.50 & 4.60\end{array}$

$\begin{array}{lll}3.39 & 3.03 & 3.75\end{array}$

$\begin{array}{lll}4.09 & 3.28 & 4.90\end{array}$

$\begin{array}{lll}4.76 & 3.98 & 5.55\end{array}$
Confirmed cases

Confirmed cases

Confirmed cases

Reported cases

Reported cases

Confirmed cases

Reported cases

Reported cases

Reported cases

Reported cases

Reported cases

Confirmed cases

Confirmed cases

Confirmed cases

Confirmed cases

Confirmed cases

Confirmed cases

Confirmed cases

Confirmed cases

Confirmed cases

Confirmed cases

Confirmed cases

Confirmed cases

Confirmed cases

Confirmed cases

Confirmed cases

Confirmed cases

Confirmed cases

Confirmed cases

Confirmed cases

Confirmed cases

Confirmed cases

Confirmed cases

Confirmed cases

Confirmed cases

Confirmed cases

Confirmed cases

Confirmed cases

Confirmed cases

Confirmed cases

Confirmed cases

Confirmed cases

Confirmed cases

Confirmed cases

Confirmed cases

Confirmed cases

Confirmed cases

Confirmed cases

Confirmed cases

Confirmed cases 
Table 2: (continued)

\begin{tabular}{|c|c|c|c|c|c|c|}
\hline Study & Study region & Study period & $\mathbf{R}_{\mathbf{0}}$ & LCL & UCL & Sources of cases \\
\hline Seth Flaxman et al. [98] & UK & $2020 / 02-2020 / 05 / 04$ & 3.82 & 3.30 & 4.34 & Confirmed cases \\
\hline Seth Flaxman et al. [98] & France & $2020 / 02-2020 / 05 / 04$ & 4.53 & 3.94 & 5.12 & Confirmed cases \\
\hline Seth Flaxman et al. [98] & Norway & $2020 / 02-2020 / 05 / 04$ & 3.04 & 2.16 & 3.92 & Confirmed cases \\
\hline Seth Flaxman et al. [98] & Belgium & $2020 / 02-2020 / 05 / 04$ & 5.16 & 3.88 & 6.45 & Confirmed cases \\
\hline Seth Flaxman et al. [98] & Austria & $2020 / 02-2020 / 05 / 04$ & 3.99 & 2.79 & 5.19 & Confirmed cases \\
\hline Seth Flaxman et al. [98] & Sweden & $2020 / 02-2020 / 05 / 04$ & 2.70 & 2.23 & 3.18 & Confirmed cases \\
\hline Seth Flaxman et al. [98] & Switzerland & $2020 / 02-2020 / 05 / 04$ & 3.26 & 2.60 & 3.93 & Confirmed cases \\
\hline Sypsa et al. [99] & Greece & $2020 / 02 / 26-2020 / 04 / 26$ & 2.38 & 2.01 & 2.80 & Confirmed cases \\
\hline Marissa L. Childs et al. [100] & USA & $2020 / 02-2021 / 07$ & 2.88 & 2.47 & 3.45 & Reported cases \\
\hline Worden et al. [101] & USA & $2020 / 01-2020 / 05$ & 1.87 & 1.38 & 2.62 & Reported cases \\
\hline Munayco et al. [77] & Peru & $2020 / 02 / 29-2020 / 03 / 30$ & 2.30 & 2.00 & 2.50 & Confirmed cases \\
\hline $\begin{array}{l}\text { Pedro Alexandre da Cruz } \\
\text { et al. [102] }\end{array}$ & Brazil & $2020 / 02 / 25-2020 / 07 / 05$ & 3.59 & 3.48 & 3.72 & Confirmed cases \\
\hline Tariq et al. [103] & Chile & $2020 / 03 / 03-2020 / 11 / 02$ & 2.58 & 0.78 & 3.99 & Confirmed cases \\
\hline $\begin{array}{l}\text { Francisco Arroyo-Marioli } \\
\text { et al. [104] }\end{array}$ & Part of the world & $2020 / 01 / 23-2020 / 05 / 06$ & 2.66 & 1.98 & 3.38 & Reported cases \\
\hline
\end{tabular}

$R_{0}$, basic reproductive number; $L C L$, lower control limit; $U C L$, upper control limit; $S E$, standard error.

interventions to control the spread of the disease [106]. Our systematic review and meta-analysis found that the overall $\mathrm{R}_{0}$ was 2.9 (95\% CI: 2.7-3.1), which is similar to the results of an earlier review of 30 articles that were based on global level evidence (2.7) [10]. However, this estimate is lower than the previously summarized $R_{0}$ values for the COVID-19 (3.15 [13] and 3.32 [9]). Our estimation is similar to the $R_{0}$ values estimated for the MERS $\left(\mathrm{R}_{0}<1-3\right)[107,108]$, and is higher than $R_{0}$ estimates for SARS $\left(R_{0}=0.58-1.17\right)$ [109]. Since the number of daily reported cases does not necessarily reflect the number of new cases on that specific date, which is because of the long reporting chain that exists between a new case and its inclusion in national or international statistics, $R_{0}$ estimates were stratified by sources of cases. Our results showed that using reported cases in the early stage of epidemic can underestimate the $R_{0}$. In our subgroup synthetic analysis, $R_{0}$ values vary among different continents, that is $\mathrm{R}_{0}$ estimates for Asia, Europe, Africa, South America, and North America varied from 2.4 to 3.1. It is noted that the total value of $R_{0}$ in a large population is the average of the $R_{0}$ subtypes, indicating $R_{0}$ is not an intrinsic characteristic of a given pathogen but rather describes the transmissibility of that pathogen within a specific population and setting [9]. In the most basic formulations of $\mathrm{R}_{0}$, its value fundamentally depends on three primary parameters: the duration of contagiousness from the infection onset, the probability of infection for each contact between a susceptible person and an infected person, and the contact rate [110]. In other words, $R_{0}$ can be viewed as a combination of the pathogen's biological constants and factors potentially influencing the contact rate, such as population density, social organization, and other epidemiological triads [61]. Because of the variation of social and human behavior among different areas, the transmission rate $(\beta)$ and the recovery rate $(\gamma)$ in epidemiological models are typically various. For example, Al-Raeei used eight countries' reported COVID-19 data to fit the same SIRD (susceptible-infectious-recovered-death) model and found the coefficient of recovery range from 0.0008 in China to 0.0981 in India [111]. In addition to the socio-behavioral factors making the $\mathrm{R}_{0}$ different in areas, the regional discrepancy of COVID-19 mutations may also produce different $\mathrm{R}_{0}$. Mercatelli et al. suggested that a significant variation existed in the distributions of COVID-19 clades in different areas around the world [25]. Viruses mutations are of considerable medical and biological relevance as it has a great impact not only in the model estimation but also in the prevention and diagnosis of infectious disease. For instance, the early analyses announced by UK Prime Minister showed that a new strain of COVID-19 could increase the reproduction number by 0.4 or more [112]. Recently, the G614 mutation in the spike protein gene (D614G) has been calling scientific attention [113]. It was recently reported that this variant exhibits more efficient infection, replication, and competitive fitness in human airway epithelial cells, but maintains similar morphology and in vitro neutralization properties, compared with the ancestral wild-type SARS-CoV-2 virus [114]. A recent study found the potential link between viral genomic variation and its impact on transmission. The G614 mutation increases the rate of transmission of SARS-CoV-2, and hence the $R_{0}$ [115]. Thus, the mutation distribution of COVID-19 in different areas should also be accounted for in the variation of estimated $\mathrm{R}_{0}$ if there are changes in the transmissibility of strains. 


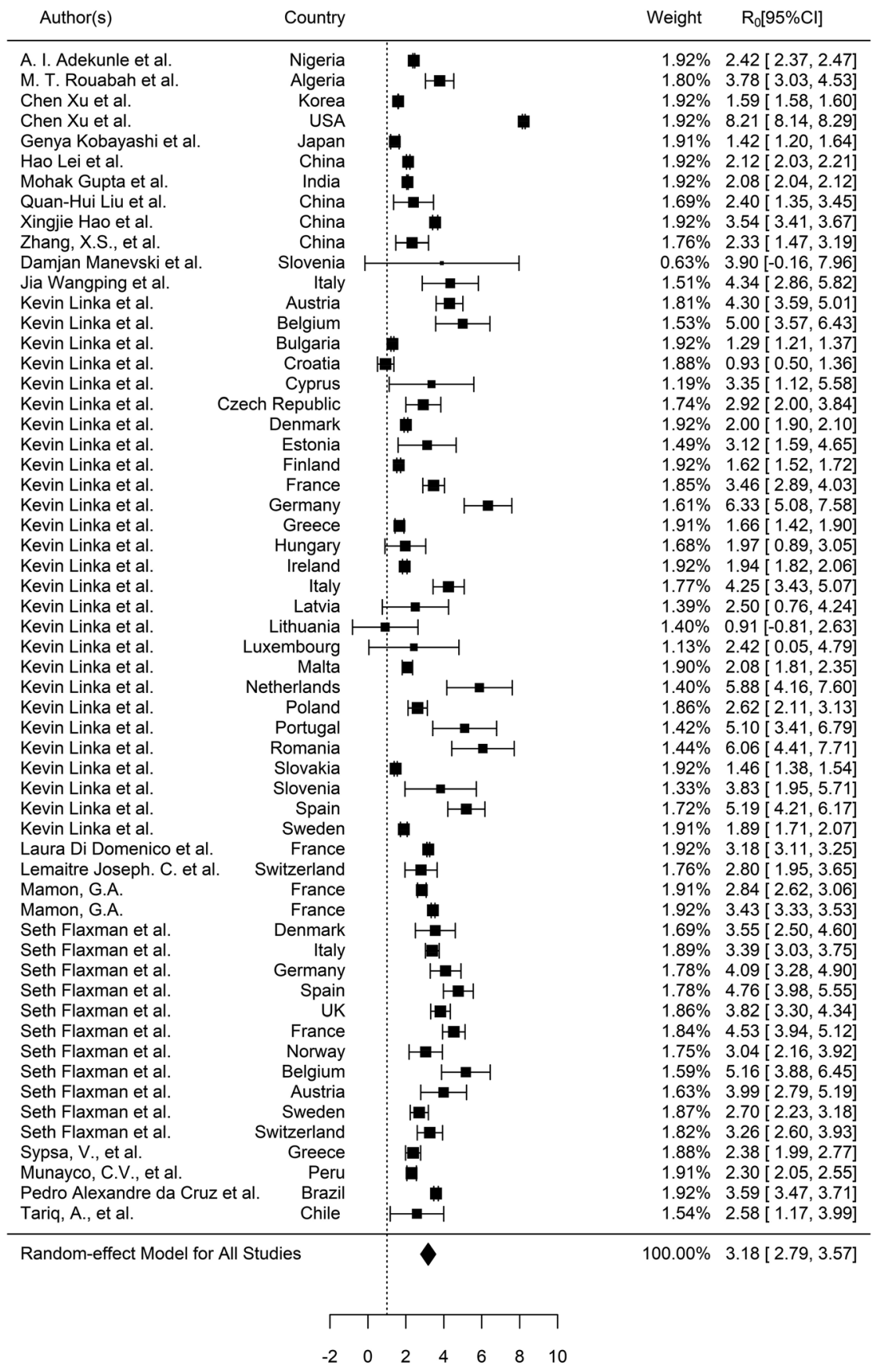

$R_{0}$

$\mathrm{R}_{0}$ estimates may be somewhat error-prone for reasons such as data insufficiency and the short period analyzed in the early stage of COVID-19. As more studies are done and more data are produced, the hope is that this error will be reduced. Thus modeling structures and assumptions may be another reason for the discrepancy of $R_{0}$ across continents. The $\mathrm{R}_{0}$ values can be estimated through a variety of models, the three most popular methods were the Stochastic dynamic model-based method, Poisson likelihoodbased (ML) method, and Exponential growth rate-based
Figure 3a: Meta-analysis of the synthetic estimated $R_{0}$ for COVID-19 with confirmed cases. $R_{0}$, the basic reproduction number. $\mathrm{Cl}$, confidence interval.

(EGR) method [116, 117]. Very few confirmed cases were reported in the early stage of the COVID-19 epidemic, which made high-quality data rarely available for mathematical models. The accuracy of $R_{0}$ values mainly depended on model structures and assumptions about demographic dynamics. For instance, Exponential Growth (EG) and maximum likelihood estimation (ML) were applied to estimate the $\mathrm{R}_{0}$ of 2019-nCoV using data of confirmed 2019-nCoV cases before January 23, 2020. The $R_{0}$ values estimated through the two different models were 2.90 


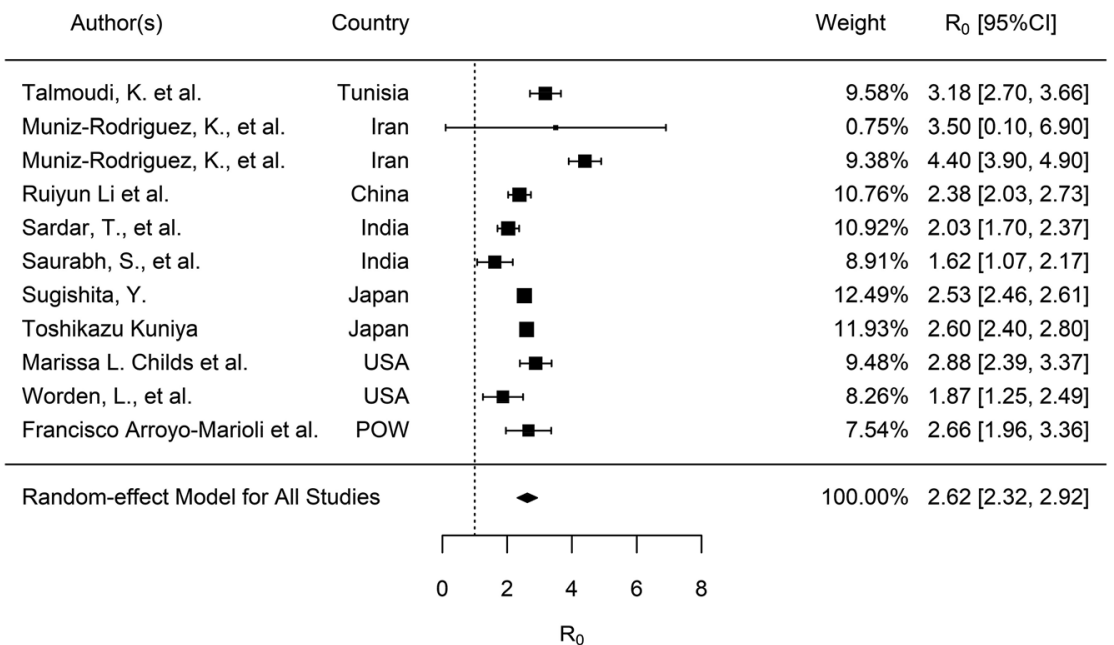

Figure 3b: Meta-analysis of the synthetic estimated $R_{0}$ for COVID-19 with reported case data. $R_{0}$, the basic reproduction number. $\mathrm{Cl}$, confidence interval.
(95\% CI: 2.32-3.63) and 2.92 (95\% CI: 2.28-3.67), respectively [118]. Hao showed the $\mathrm{R}_{0}$ value was about 3.5 according to the MSEIR model and about 1.5 according to the MSIR model utilizing the COVID-19 data from January 21 to February 17, 2020 [119].

In addition, the estimation accuracy of $R_{0}$ was sensitive to the epidemiological parameterizations of models, which can be a reason for different $R_{0}$ estimates in the same countries as well. Mohammad et al. [8] demonstrated that COVID-19 $R_{0}$ is sensitive to the applied mean generation time when they estimated $R_{0}$ in Qom, Iran. Zhou et al. [105] showed the value of $R_{0}$ for SARS-CoV-2 was most sensitive to the generation time, so the more accurate estimation of the generation time based on the accumulation of epidemiological survey data would further improve the quality of the estimation of $R_{0}$. For other pathogens, $R_{0}$ values can be sensitive to model parameters as well. It was shown that $\mathrm{R}_{0}$ for SARS was most sensitive to the transmission rate and the relative infectiousness after isolation in hospitals [109]. A study of Echinococcosis in Xinjiang, China found that the initial value $S_{H}(0)$ can influence the $R_{0}$ most compared to $S_{D}(0), I_{D}(0)$, and other initial conditions [120].

\section{Public health measures against COVID-19}

\section{Time-dependent reproduction number $\left(\boldsymbol{R}_{t}\right)$ and intervention evaluation}

Different from $R_{0}$, the time-dependent reproductive number $\left(R_{t}\right)$ or the effective reproductive number $\left(R_{e}\right)$ can be utilized to partly achieve an explanation of the time course of an epidemic. $R_{t}$ is defined as the actual average number of secondary cases per primary case at calendar time $t$ (for $\mathrm{t}>0$ ), which shows time-dependent variation due to the decline in susceptible individuals (intrinsic factors) and the implementation of control measures (extrinsic factors). If $\mathrm{R}(\mathrm{t})<1$, it suggests that the epidemic is in decline and may be regarded as being under control at time $t$, which make $R_{t}$ be used to characterize transmissibility once a certain proportion of the population has been infected and is resistant (immune) [121]. As $R_{t}$ is similar to $R_{0}$ in that it is a population-averaged value, it can also be estimated via a broad range of models. While common misinterpretation and misconceptions about $R_{t}$ and $R_{0}$ have been addressed [61], some misunderstandings and confusion persist [62]. With the evolution of the pandemic, the $R_{t}$ can reduce as a result of the implementation of active measures or utilization of vaccination, thus $R_{t}$ can be used to measure the effectiveness of vaccination campaigns or other public health interventions [122].

\section{Varying approaches of containment measures against COVID-19}

To inform recommendations for control measures and determine the impact of varied intervention measures put in place, we reviewed $R_{t}$ estimates in countries or regions across five continents. 1350 studies we identified were searched from several online databases as we describe in "Epidemiological dynamics of SARS-CoV-2" section. Studies were included if they presented a mathematical/ statistical model of SARS-CoV-2 and reported $R_{0} / R_{t}$. Reports were excluded in this section if they met the criteria $b$ ), c), d), e) and f) mentioned in "Search strategy and selection criteria” section. The median $\mathrm{R}_{\mathrm{t}}$ was 1.0 (IQR, 0.7-1.6) for all the reviewed studies. After being stratified by continents, 


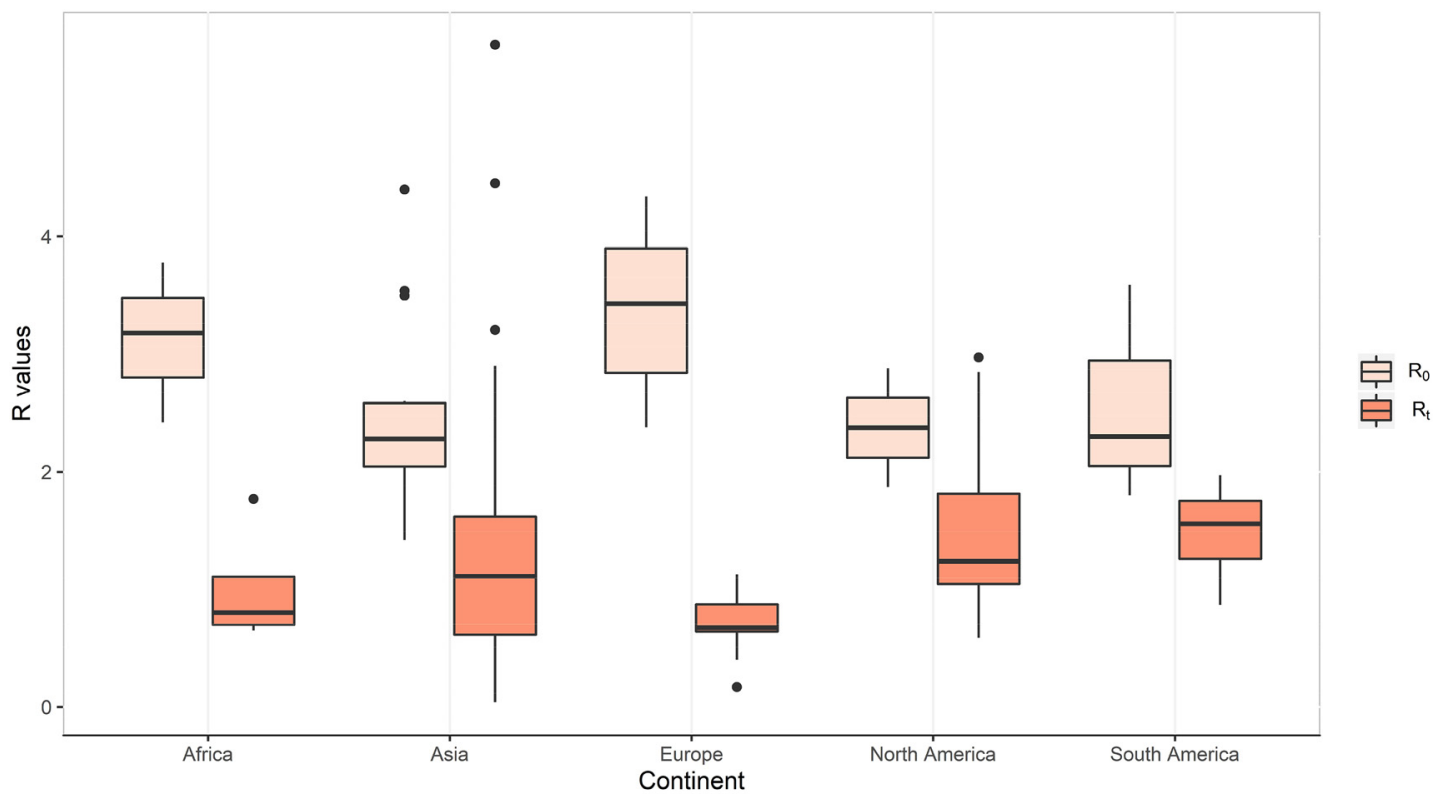

Figure 4: Boxplot of $R_{0}$ and $R_{t}$ metrics across continents. $R_{0}$, the basic reproduction number. $R_{t}$, the time-dependent reproduction number.

Median $\mathrm{R}_{\mathrm{t}}$ for Asia, Europe, Africa, South America, and North America were 1.1 (IQR, 0.6-1.6), 0.7 (IQR, 0.6-0.9), 0.8 (IQR, 0.7-1.1), 1.6 (IQR, 1.3-1.8) and 1.2 (IQR, 1.0-1.8), respectively. Estimated $R_{t}$ values are lowest for Europe, followed by those for Africa, Asia, and North and South America. As demonstrated in Figure 4, the decrease of reproductive numbers varies across continents, which may imply the different effectiveness of containment measures taken by different countries. Thus, we extract studies reporting $\mathrm{R}_{0}$ with $95 \% \mathrm{CI}$ and $\mathrm{R}_{\mathrm{t}}$ with $95 \% \mathrm{CI}$ to evaluate control measures in the 40 specific countries (see Figure 5).

\section{Comprehensive interventions}

Some countries took comprehensive control interventions against COVID-19. A study on the impact of interventions in limiting COVID-19 transmission in Sichuan, China estimated the number of cases averted by the implemented control strategies [86]. The outbreak resulted in 539 confirmed cases, lasted less than two months, and no further local transmission was detected after February 27. It may be attributed to a strict set of measures by the Sichuan government to deal with the outbreak, including case isolation, tracing and screening of contacts of confirmed cases, quarantine of travelers from affected areas, and screening of people's temperature in public places [86]. According to a study by Lemaitre et al., Large-scale non-pharmaceutical interventions (NPIs) were implemented by the cantons and the federal government between 28 February and 20 March 2020 in Switzerland, including a set of measures: (1) ban on gatherings of more than 1,000 people, (2) school closure, (3) closure of non-essential activities, and (4) ban on gatherings of more than five people [96]. As a result, the national $\mathrm{R}_{0}$ was to be 2.8 ( $95 \% \mathrm{CI}: 2.1-3.8$ ) at the beginning of the epidemic. Starting from around $7 \mathrm{March}$, a strong reduction in reproductive number was found, with an 85.7\% median decrease [96] (Table 3). Research suggests that the reproductive number of SARS-CoV-2 decreased by $95.6 \%$ since the adoption of NPIs, showing that NPIs were effective also in Slovenia for controlling SARS-CoV-2 (Table 3). $R_{t}$ estimates of China, Japan, and 11 European countries were all below 0.5 (Figure 5), indicating that each sick person may infect fewer than 0.5 people on average, and the number of infected individuals may shrink over time. Generally, it will benefit a lot to implement early and continuing comprehensive interventions [123]. Nowadays, a large number of countries worldwide have conducted contact tracing to help identify infected people and contain the spread of COVID-19. In some countries, tracing "contact of a contact" has been used as well, which means any individual who is a contact of proximate contacts (i.e. spouse, children, co-workers, etc.) would be at risk and subject to quarantine once the proximate contacts had or developed symptoms, or tested positive for the virus causing COVID-19. This measure was always combined with modern technologies, such as cell phones, closed-circuit television (CCTV), and bank transactions, which helps collect information in an effective way, but privacy concerns and some ethical questions about exposing peoples' activities and movements have been also raised [124]. 


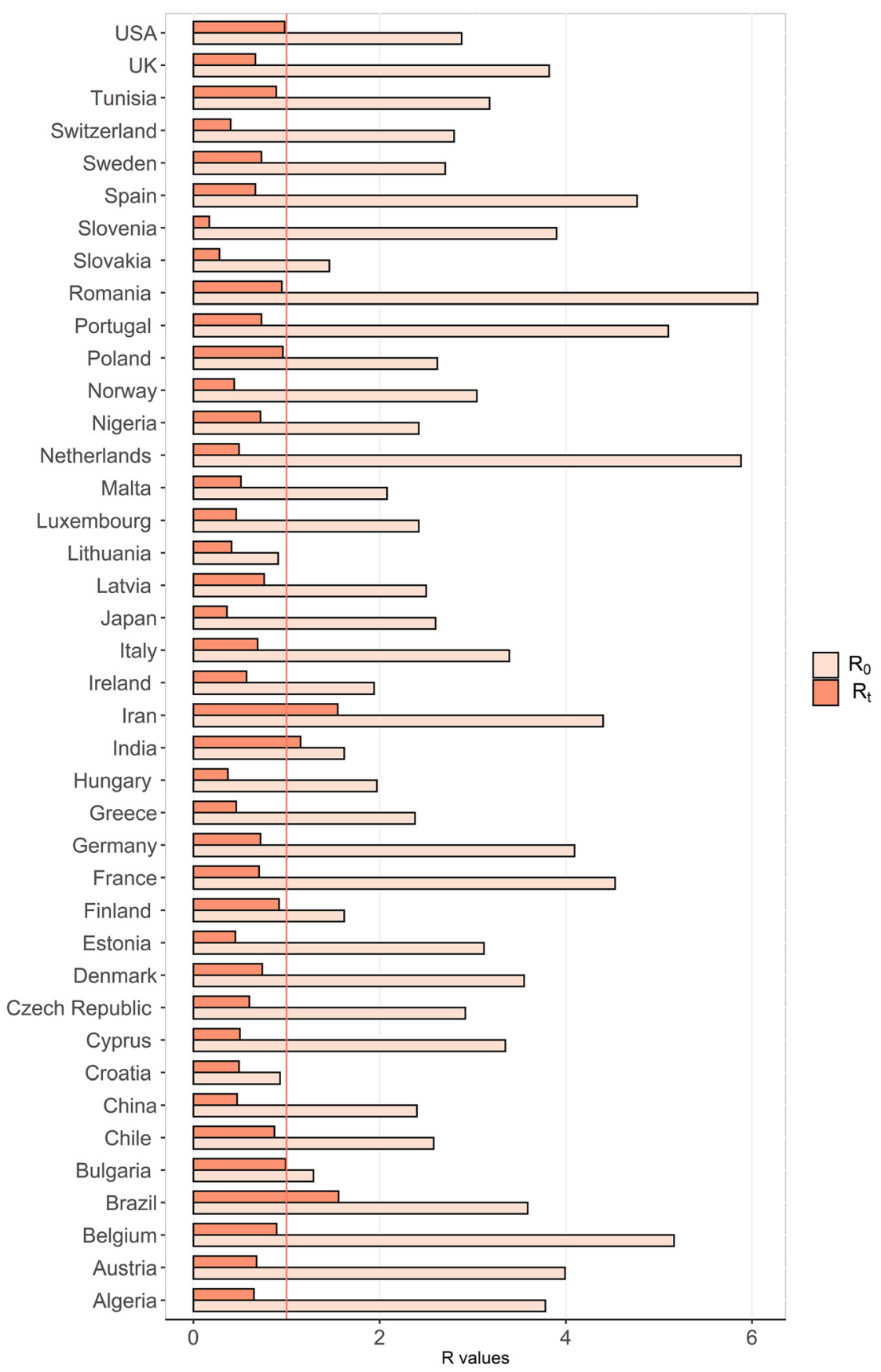

Figure 5: Comparison of $R_{0}$ and $R_{t}$ metrics across countries. $R_{0}$, the basic reproduction number; $R_{t}$, the timedependent reproduction number.

\section{Lockdown}

Strict strategies of lockdown were imposed in some countries $[80,81,99,103]$. For instance, a report of Chile on the effectiveness of lockdowns estimated that the reproductive number declined by $66.3 \%$ and reached 0.9 during lockdown (Table 3), indicating that the control measures at the start of the epidemic significantly slowed down the spread of the virus [103]. Large changes in $R_{t}$ in response to the combined lockdown interventions were estimated for Tunisia as well [81]. The $R_{t}$ moves to 0.89 (95\% CI: $0.84-0.94$ ) by the national lockdown measure, which is under the epidemic threshold 1 (Table 3). A nationwide lockdown restricting all nonessential movement throughout Greece began on March 23. A survey showed that before measures were implemented, the estimated $\mathrm{R}_{0}$ was 2.38 (95\% CI 2.01-2.80) [99]. During the lockdown, daily contacts decreased by $86.9 \%$ and reproductive numbers decreased by $81.0 \%$ (Table 3 ). A total lockdown intervention applied in Algeria was effective in 
Table 3: Summary of public health interventions against COVID-2019 in countries.

\begin{tabular}{|c|c|c|c|c|c|c|}
\hline Country & Interventions & Type & Start date & End date & $\begin{array}{r}\text { Implementing } \\
\text { period, days }\end{array}$ & $\begin{array}{r}\text { The reproduc- } \\
\text { tive number } \\
\text { reduction, \% }\end{array}$ \\
\hline Algeria & Lockdown & Lockdown & $2020 / 3 / 24$ & $2020 / 5 / 24$ & 61 & 82.80 \\
\hline Austria & $\begin{array}{l}\text { Case based self-isolation mandated, Social } \\
\text { distancing encouraged, Public events banned, } \\
\text { School closure ordered, Lockdown ordered }\end{array}$ & $\begin{array}{l}\text { Comprehensive } \\
\text { interventions }\end{array}$ & $2020 / 3 / 10$ & $2020 / 5 / 4$ & 55 & 83.01 \\
\hline Belgium & $\begin{array}{l}\text { Case based self-isolation mandated, Social } \\
\text { distancing encouraged, Public events banned, } \\
\text { School closure ordered, Lockdown ordered }\end{array}$ & $\begin{array}{l}\text { Comprehensive } \\
\text { interventions }\end{array}$ & $2020 / 3 / 10$ & $2020 / 5 / 4$ & 55 & 82.67 \\
\hline Brazil & Quarantine and social distancing & $\begin{array}{l}\text { Isolation and } \\
\text { social distance }\end{array}$ & $2020 / 5 / 31$ & $2020 / 7 / 5$ & 35 & 56.50 \\
\hline Bulgaria & $\begin{array}{l}\text { Public health interventions including isolation } \\
\text { quarantine, physical distancing, and commu- } \\
\text { nity containment. }\end{array}$ & $\begin{array}{l}\text { Comprehensive } \\
\text { interventions }\end{array}$ & $2020 / 3 / 17$ & $2020 / 5 / 10$ & 54 & 23.26 \\
\hline Chile & Total lockdown & Lockdown & $2020 / 5 / 5$ & $2020 / 7 / 19$ & 75 & 66.28 \\
\hline China & $\begin{array}{l}\text { A set of measures; School closure; suspension } \\
\text { of gathering activities and entertainment; case } \\
\text { isolation, tracing and screening of contacts of } \\
\text { confirmed cases, quarantine of travellers from } \\
\text { affected areas, and screening of people's } \\
\text { temperature in public places. }\end{array}$ & $\begin{array}{l}\text { Comprehensive } \\
\text { interventions }\end{array}$ & $2020 / 1 / 24$ & $2020 / 4 / 19$ & 86 & 80.40 \\
\hline Croatia & $\begin{array}{l}\text { Public health interventions including isolation } \\
\text { quarantine, physical distancing, and commu- } \\
\text { nity containment. }\end{array}$ & $\begin{array}{l}\text { Comprehensive } \\
\text { interventions }\end{array}$ & $2020 / 3 / 16$ & $2020 / 5 / 10$ & 55 & 47.31 \\
\hline Cyprus & $\begin{array}{l}\text { Public health interventions including isolation } \\
\text { quarantine, physical distancing, and commu- } \\
\text { nity containment. }\end{array}$ & $\begin{array}{l}\text { Comprehensive } \\
\text { interventions }\end{array}$ & $2020 / 3 / 10$ & $2020 / 5 / 10$ & 61 & 85.07 \\
\hline $\begin{array}{l}\text { Czech } \\
\text { Republic }\end{array}$ & $\begin{array}{l}\text { Public health interventions including isolation } \\
\text { quarantine, physical distancing, and commu- } \\
\text { nity containment. }\end{array}$ & $\begin{array}{l}\text { Comprehensive } \\
\text { interventions }\end{array}$ & $2020 / 3 / 10$ & $2020 / 5 / 10$ & 61 & 79.45 \\
\hline Denmark & $\begin{array}{l}\text { Case based self-isolation mandated, Social } \\
\text { distancing encouraged, Public events banned, } \\
\text { School closure ordered, Lockdown ordered }\end{array}$ & $\begin{array}{l}\text { Comprehensive } \\
\text { interventions }\end{array}$ & $2020 / 3 / 12$ & $2020 / 5 / 4$ & 53 & 79.18 \\
\hline Estonia & $\begin{array}{l}\text { Public health interventions including isolation } \\
\text { quarantine, physical distancing, and commu- } \\
\text { nity containment. }\end{array}$ & $\begin{array}{l}\text { Comprehensive } \\
\text { interventions }\end{array}$ & $2020 / 3 / 12$ & $2020 / 5 / 10$ & 59 & 85.70 \\
\hline Finland & $\begin{array}{l}\text { Public health interventions including isolation } \\
\text { quarantine, physical distancing, and commu- } \\
\text { nity containment. }\end{array}$ & $\begin{array}{l}\text { Comprehensive } \\
\text { interventions }\end{array}$ & $2020 / 3 / 12$ & $2020 / 5 / 10$ & 59 & 43.21 \\
\hline France & $\begin{array}{l}\text { Case based self-isolation mandated, Social } \\
\text { distancing encouraged, Public events banned, } \\
\text { School closure ordered, Lockdown ordered }\end{array}$ & $\begin{array}{l}\text { Comprehensive } \\
\text { interventions }\end{array}$ & $2020 / 3 / 13$ & $2020 / 5 / 4$ & 52 & 84.42 \\
\hline Germany & $\begin{array}{l}\text { Case based self-isolation mandated, Social } \\
\text { distancing encouraged, Public events banned, } \\
\text { School closure ordered, Lockdown ordered }\end{array}$ & $\begin{array}{l}\text { Comprehensive } \\
\text { interventions }\end{array}$ & $2020 / 3 / 6$ & $2020 / 5 / 4$ & 59 & 82.41 \\
\hline Greece & Nationwide lockdown & Lockdown & $2020 / 3 / 23$ & $2020 / 4 / 26$ & 34 & 80.70 \\
\hline Hungary & $\begin{array}{l}\text { Public health interventions including isolation } \\
\text { quarantine, physical distancing, and commu- } \\
\text { nity containment. }\end{array}$ & $\begin{array}{l}\text { Comprehensive } \\
\text { interventions }\end{array}$ & $2020 / 3 / 11$ & $2020 / 5 / 10$ & 60 & 81.22 \\
\hline India & Home isolation of asymptomatic & $\begin{array}{l}\text { Isolation and } \\
\text { social distance }\end{array}$ & $2020 / 5 / 10$ & $2020 / 7 / 6$ & 57 & 29.00 \\
\hline Iran & Social distancing & $\begin{array}{l}\text { Isolation and } \\
\text { social distance }\end{array}$ & $2020 / 3 / 6$ & $2020 / 3 / 19$ & 13 & 64.80 \\
\hline Ireland & Public health interventions including isolation & Comprehensive & $2020 / 3 / 13$ & $2020 / 5 / 10$ & 58 & 70.62 \\
\hline
\end{tabular}
quarantine, physical distancing, and commu- interventions nity containment. 
Table 3: (continued)

\begin{tabular}{|c|c|c|c|c|c|c|}
\hline Country & Interventions & Type & Start date & End date & $\begin{array}{r}\text { Implementing } \\
\text { period, days }\end{array}$ & $\begin{array}{r}\text { The reproduc- } \\
\text { tive number } \\
\text { reduction, \% }\end{array}$ \\
\hline Italy & $\begin{array}{l}\text { Case based self-isolation mandated, Social } \\
\text { distancing encouraged, Public events banned, } \\
\text { School closure ordered, Lockdown ordered }\end{array}$ & $\begin{array}{l}\text { Comprehensive } \\
\text { interventions }\end{array}$ & $2020 / 3 / 5$ & $2020 / 5 / 4$ & 60 & 79.69 \\
\hline Japan & Declaration of a state of emergency & Others & $2020 / 4 / 7$ & $2020 / 5 / 25$ & 48 & 86.20 \\
\hline Latvia & $\begin{array}{l}\text { Public health interventions including isolation } \\
\text { quarantine, physical distancing, and commu- } \\
\text { nity containment. }\end{array}$ & $\begin{array}{l}\text { Comprehensive } \\
\text { interventions }\end{array}$ & $2020 / 3 / 13$ & $2020 / 5 / 10$ & 58 & 69.60 \\
\hline Lithuania & $\begin{array}{l}\text { Public health interventions including isolation } \\
\text { quarantine, physical distancing, and commu- } \\
\text { nity containment. }\end{array}$ & $\begin{array}{l}\text { Comprehensive } \\
\text { interventions }\end{array}$ & $2020 / 3 / 16$ & $2020 / 5 / 10$ & 55 & 85.70 \\
\hline Luxembourg & $\begin{array}{l}\text { Public health interventions including isolation } \\
\text { quarantine, physical distancing, and commu- } \\
\text { nity containment. }\end{array}$ & $\begin{array}{l}\text { Comprehensive } \\
\text { interventions }\end{array}$ & $2020 / 3 / 13$ & $2020 / 5 / 10$ & 58 & 80.99 \\
\hline Malta & $\begin{array}{l}\text { Public health interventions including isolation } \\
\text { quarantine, physical distancing, and commu- } \\
\text { nity containment. }\end{array}$ & $\begin{array}{l}\text { Comprehensive } \\
\text { interventions }\end{array}$ & $2020 / 3 / 13$ & $2020 / 5 / 10$ & 58 & 75.48 \\
\hline Netherlands & $\begin{array}{l}\text { Public health interventions including isolation } \\
\text { quarantine, physical distancing, and commu- } \\
\text { nity containment. }\end{array}$ & $\begin{array}{l}\text { Comprehensive } \\
\text { interventions }\end{array}$ & $2020 / 3 / 12$ & $2020 / 5 / 10$ & 59 & 91.67 \\
\hline Nigeria & International travel ban & Others & $2020 / 3 / 20$ & $2020 / 5 / 7$ & 48 & 70.20 \\
\hline Norway & $\begin{array}{l}\text { Case based self-isolation mandated, Social } \\
\text { distancing encouraged, Public events banned, } \\
\text { School closure ordered }\end{array}$ & $\begin{array}{l}\text { Comprehensive } \\
\text { interventions }\end{array}$ & $2020 / 3 / 12$ & $2020 / 5 / 4$ & 53 & 85.70 \\
\hline Poland & $\begin{array}{l}\text { Public health interventions including isolation } \\
\text { quarantine, physical distancing, and commu- } \\
\text { nity containment. }\end{array}$ & $\begin{array}{l}\text { Comprehensive } \\
\text { interventions }\end{array}$ & $2020 / 3 / 12$ & $2020 / 5 / 10$ & 59 & 63.36 \\
\hline Portugal & $\begin{array}{l}\text { Public health interventions including isolation } \\
\text { quarantine, physical distancing, and commu- } \\
\text { nity containment. }\end{array}$ & $\begin{array}{l}\text { Comprehensive } \\
\text { interventions }\end{array}$ & $2020 / 3 / 12$ & $2020 / 5 / 10$ & 59 & 85.69 \\
\hline Romania & $\begin{array}{l}\text { Public health interventions including isolation } \\
\text { quarantine, physical distancing, and commu- } \\
\text { nity containment. }\end{array}$ & $\begin{array}{l}\text { Comprehensive } \\
\text { interventions }\end{array}$ & $2020 / 3 / 11$ & $2020 / 5 / 10$ & 60 & 84.32 \\
\hline Slovakia & $\begin{array}{l}\text { Public health interventions including isolation } \\
\text { quarantine, physical distancing, and commu- } \\
\text { nity containment. }\end{array}$ & $\begin{array}{l}\text { Comprehensive } \\
\text { interventions }\end{array}$ & $2020 / 3 / 12$ & $2020 / 5 / 10$ & 59 & 80.82 \\
\hline Slovenia & Non-pharmaceutical interventions (NPIs) & $\begin{array}{l}\text { Comprehensive } \\
\text { interventions }\end{array}$ & $2020 / 3 / 10$ & $2020 / 4 / 30$ & 51 & 95.60 \\
\hline Spain & $\begin{array}{l}\text { Case based self-isolation mandated, Social } \\
\text { distancing encouraged, Public events banned, } \\
\text { School closure ordered, Lockdown ordered }\end{array}$ & $\begin{array}{l}\text { Comprehensive } \\
\text { interventions }\end{array}$ & $2020 / 3 / 9$ & $2020 / 5 / 4$ & 56 & 86.02 \\
\hline Sweden & $\begin{array}{l}\text { Case based self-isolation mandated, Social } \\
\text { distancing encouraged, Public events banned, } \\
\text { School closure ordered, Lockdown ordered }\end{array}$ & $\begin{array}{l}\text { Comprehensive } \\
\text { interventions }\end{array}$ & $2020 / 3 / 10$ & $2020 / 5 / 4$ & 55 & 73.01 \\
\hline Switzerland & $\begin{array}{l}\text { Large-scale non-pharmaceutical interventions } \\
\text { (NPIs): School closure; banned gatherings of } \\
\text { more than five people and recommended } \\
\text { voluntary home isolation for the whole } \\
\text { population. }\end{array}$ & $\begin{array}{l}\text { Comprehensive } \\
\text { interventions }\end{array}$ & $2020 / 2 / 28$ & $2020 / 3 / 20$ & 21 & 85.70 \\
\hline Tunisia & Lockdown & Lockdown & $2020 / 3 / 22$ & $2020 / 5 / 5$ & 44 & 72.00 \\
\hline UK & $\begin{array}{l}\text { Case based self-isolation mandated, Social } \\
\text { distancing encouraged, Public events banned, } \\
\text { School closure ordered, Lockdown ordered }\end{array}$ & $\begin{array}{l}\text { Comprehensive } \\
\text { interventions }\end{array}$ & $2020 / 3 / 12$ & $2020 / 5 / 4$ & 53 & 82.58 \\
\hline USA & Shelter-in-place orders & $\begin{array}{l}\text { Isolation and } \\
\text { social distance }\end{array}$ & $2020 / 3 / 17$ & $2020 / 7 / 1$ & 106 & 66.00 \\
\hline
\end{tabular}

Decrease of the reproductive number $(\%)=\left(R_{0}-R_{t}\right) / R_{0} \times 100 \%$. 
Algeria with a reduction of transmission by $82.8 \%$ [80] (Table 3). As shown in Figure 5, $\mathrm{R}_{\mathrm{t}}$ estimates of Algeria, Greece, Tunisia, and Chile taking a control measure of lockdown were all below 1. Practically, a lockdown decision can have very extensive effects, it is also dependent on how prepared a country is in the early phases of the pandemic [125]. Moreover, the uneven enforcement of central and local authorities in each country has led to different outcomes. Simply lockdowns without adequate testing, targeted quarantines or other interventions will not be effective in the long run [126].

\section{Isolation and social distance}

Many countries adopted control measures of isolation and social distance. A study in Santa Clara County, California, the US estimated a shift to partial social distancing, combined with rigorous testing and isolation of symptomatic individuals, is a viable alternative to indefinitely maintaining shelter-in-place. It also estimated that if Santa Clara County had waited one week longer before issuing shelterin-place orders, 95 additional people would have died by April 22 [100]. Similarly, a report in Iran estimated the reproduction number as 4.4 (95\% CI: 3.9-4.9) by using a generalized growth model, and the reproduction number was 1.55 after social distancing interventions were implemented, with a decrease of $64.8 \%$ [76]. Literature shows that if social distancing measures are not respected, a difference of at least 100,000 cases may occur over the next 300 days in Brazil [102]. A report in Jodhpur, Rajasthan, in the northwestern part of India suggests that control measures of isolation can reduce transmission by $29.0 \%$ [88], which is lower than that of the USA, Iran, and Brazil (Table 3). It is noted that implementing period of home isolation in India was 57 days, almost two times the period of quarantine in Brazil, but the reduction of reproduction number in India was only half that of Brazil (Table 3). It may owe to the poor consciousness among the people. They may not take it seriously and go back to taking part in social functions without adhering to protocols and appropriate behavior. Strengthening propaganda and following the COVID-19 appropriate behavior continuously, the effectiveness of control measures will get better. In summary, compared with comprehensive interventions and lockdowns, taking only a measure of isolation likely is much less effective for SARS-CoV-2, which agrees with studies by Davies et al. [127] and Flaxman et al. [98]. It is noted that $\mathrm{R}_{\mathrm{t}}$ estimates of Iran, Brazil, India and USA taking control measures of isolation and social distance were around 1 or over.

\section{Other public health interventions}

Other protection measures were taken as well. The Japanese government declared a state of emergency on April 7, 2020 since the serious growth of the daily number of newly reported cases started in late March [128]. The $\mathrm{R}_{\mathrm{t}}$ during the period of the state of emergency was estimated to be 0.36 , with a reduction in the reproductive number of $86.2 \%$ (Table 3), suggesting the state of emergency might have been highly effective on the first wave of COVID-19 in Japan [90]. A study in Nigeria implied that the measure of international travel ban put in place have not been effective enough, because it could only help reduce the relative infectiousness of imported cases, with a $70.2 \%$ decrease of transmission (Table 3). Efforts must be concentrated on ensuring that the existing measures are improved and additional measures better than the existing ones can be introduced [79].

\section{COVID-19 vaccines}

\section{Strategies for COVID-19 vaccine development}

The WHO has issued a target product profile that specifies the characteristics of an ideal vaccine [129]. And the US Food and Drug Administration has also issued a guidance document on COVID-19 vaccines [130]. Overall, both these documents require the ideal vaccine should have: a) an excellent safety profile suitable for multiple population groups, such as elderly, children, and pregnant women; b) no contraindications and minimal adverse events; c) at least $70 \%$ efficacy ideally within 2 weeks, and d) long-lasting protection that last for at least 1 year. Along with these guidelines, dozens of research teams have been involved in the development of the COVID-19 vaccine. From the experience of vaccine development for the previous MERS and SARS epidemic, we can summarize the strategies used by these research groups into six strategies, and each pipeline has its advantages and disadvantages (see Table 4) [131].

\section{Live attenuated virus vaccine}

This is the most traditional technology used for vaccine development. It can provide the most immunogenic vaccine formations since the weakened microbes retain the ability to replicate in vivo. It has the ability to stimulate the immune system by inducing the toll-like receptors (TLRs) that involve B cells, CD4, and CD8 T cells [132]. However, this 
Table 4: Advantages and disadvantages of different COVID-19 vaccine pipelines.

\begin{tabular}{|c|c|c|}
\hline $\begin{array}{l}\text { Vaccine } \\
\text { pipelines }\end{array}$ & Advantages & Disadvantages \\
\hline $\begin{array}{l}\text { Attenuated } \\
\text { virus vaccine }\end{array}$ & $\begin{array}{l}\text { Induce a strong and } \\
\text { persistent immune } \\
\text { memory }\end{array}$ & $\begin{array}{l}\text { The attenuation of viruses } \\
\text { is complex; } \\
\text { Can be associated with } \\
\text { significant side effects }\end{array}$ \\
\hline $\begin{array}{l}\text { Inactivated } \\
\text { virus vaccine }\end{array}$ & $\begin{array}{l}\text { Safer than live attenu- } \\
\text { ated virus; } \\
\text { Has development } \\
\text { foundation }\end{array}$ & $\begin{array}{l}\text { Long production time; } \\
\text { Immunity duration may be } \\
\text { short }\end{array}$ \\
\hline $\begin{array}{l}\text { Viral vectored } \\
\text { vaccine }\end{array}$ & $\begin{array}{l}\text { Strong immune } \\
\text { response; } \\
\text { Mimicking natural } \\
\text { infection }\end{array}$ & $\begin{array}{l}\text { Complicated } \\
\text { manufacturing process; } \\
\text { Immunity against the } \\
\text { vector; } \\
\text { Risk of genomic integration }\end{array}$ \\
\hline $\begin{array}{l}\text { Protein sub- } \\
\text { unit vaccine }\end{array}$ & Safe and well-tolerated & Lower immunogenicity \\
\hline DNA vaccine & $\begin{array}{l}\text { Safe and well- } \\
\text { tolerated; } \\
\text { Cold-chain free }\end{array}$ & $\begin{array}{l}\text { Lower immunogenicity; } \\
\text { Risk of genomic integration }\end{array}$ \\
\hline RNA vaccine & Safe and well-tolerated & $\begin{array}{l}\text { Instability; } \\
\text { The potential risk of } \\
\text { RNA-induced interferon } \\
\text { response }\end{array}$ \\
\hline
\end{tabular}

comes at the cost of safety issues, including the possibility of reversion to a virulent state and the risk of significant side effects [133]. Thereby, this kind of vaccine needs to be carefully assessed before proceeding to clinical use, and their storage and handling require strict procedures.

The WHO listed three preclinical ongoing studies focusing on live attenuated vaccine development [134]. The Serum Inst of India in collaboration with Codagenix Inc is developing a live attenuated vaccine based on their CodaVax technology. Accessible safety and immunogenicity of the Influenza vaccine in animal models were documented by using this technology [135]. The University of Hong Kong also starts from an influenza-based vaccine strain with a deletion in the NS1 gene (DelNS1SARS-CoV2-RBD). They re-organized the gene to express the RBD domain of SARS-CoV-2 spike protein and cultivated it in the Madin Darby Canine Kidney Cells [132]. The University of Mehmet Ali Aydunar in Turkey and Indian Immunologicals Ltd in India also have projects on attenuated COVID-19 vaccines, while none of these vaccine candidates have stepped into phase three clinical trials.

\section{Inactivated whole-virus vaccine}

Vaccines that use inactivated microorganisms to induce immune response also have a very long history. Although it is a whole (killed) virus, it does not have the risk of viral reactivation compared with live attenuated viruses. Moreover, this vaccine is effective on multiple SARS-CoV-2 antigens, including the $\mathrm{S}$ protein. Therefore, the inactivated virus is stable and safe compared to live attenuated viruses [136]. A phase 2 clinical trial only reported mild side effects, such as localized injection site redness and pain, while all had resolved within $72 \mathrm{~h}$ [137]. There are strong research foundations of inactivated SARS-CoV-2 because this strategy has already been tested for SARS-CoV and many other diseases, such as Cholera, Hepatitis A virus, Plague, and the like. However, several limitations made inactivated whole-virus vaccines less attractive. First, it needs a long time to produce a dose of this kind of vaccine, so that it is not appealing enough in the timesensitive race of COVID-19 vaccine development [138]. Besides, whole-inactivated vaccines have to be manufactured in biosafety level three-capable facilities, which will also cause difficulties for some areas [139]. Second, the duration of immunity is short that demands inoculation of higher amounts of vaccine with an adjuvant [136]. Third, the inactivation process may also structurally deforms the immunogenic epitopes of inactivated viruses which can disable the vaccine [131].

Although the inactivated whole-virus has some disadvantages, the proper combination of the inactivation method and adjuvants can also produce a satisfactory preventive effect. Sinopharm and Sinovac choose alum as the adjuvant $[139,140]$. Among those inactivated candidates, the most promising inactivated COVID-19 vaccine candidates are in China [138]: CoronaVac/ PiCoVacc (Registry index: NCT04456595NCT04582344), Inactivated COVID-19 vaccine (Vero cells) (Registry index: ChiCTR2000034780), and BBIBP-CoV (Registry index: NCT04560881 ChiCTR2000034780) have all stepped into phase 3 clinical trials.

\section{Viral vectored vaccine}

Viral vectored vaccines are another type of live attenuated vaccine. Viral vectors that cannot replicate in human cells are inserted specific DNA to induce a strong antigen-specific immune response. Although some replication active vectors can also be exploited as viral vector vaccines, they will not trigger any other disease. Ura et al. suggested that this kind of vaccine is highly specific in delivering the genes to the target cells, highly efficient in gene transduction, and induces immunity [132, 141]. Because researchers are only exposed to viruses and DNA that do not cause diseases, the risk of laboratory infection is greatly reduced. Some drawbacks also exist in the process of viral vectored vaccines 
production. Because we need to insert only DNA into viral vectors, including cellular system optimization and contaminants exclusion, complicated technologies are needed to ensure the efficiency of viral vectors [142]. Moreover, preexisting immunity on the viral vector may affect vaccine efficacy. For instance, the most widely used vectors for COVID-19 vaccines are adenoviral-based. Most patients may have pre-existing immunity against the adenovirus, and the immune response to SARS-CoV-2 may be dampened [143]. Last, there is a risk of genomic integration of recombinant viruses into the host which may lead to cancer, and additional long-term biosafety assessment is required.

Kaur et al. [132] suggested that viral vector vaccines had great potential for prophylactic use. There are some candidates in phase 3 clinical trials. ChAdOx1 (NCT04516746NCT04540393) was developed by the University of Oxford, and the Adenovirus vector genome is formatted by inserting the SARS-CoV-2 spike gene into the E1 locus of the ChAdOx1 adenovirus genome. Ad5-nCoV (NCT04526990NCT04540419) developed by the Beijing Ins of Biotechnology was constructed by the Admax system from the Microbix Biosystem [144]. Both RBD and spike protein-specific neutralizing antibody increases were observed within two weeks of immunization, whereas the pre-existing anti-Ad5 immunity would limit the immune response [144]. Beyond these two projects, GamCOVID-Vac (NCT04530396NCT04564716) and Ad26.COV2.S (NCT04505722) also have the potential of being marketed within a short time.

\section{Protein subunit vaccine}

This kind of vaccine consists of viral proteins or protein fragments. Because it does not have any live component of the viral particle, it is one of the safest candidates with fewer and milder side effects. For the biosafety for a new virus causing a global pandemic, numerous vaccine projects are focusing on the SARS-CoV-2 proteins and their fragments. As a cost of safety, the subunit vaccine can only induce limited immunity and requires auxiliary adjuvant to activate a robust immune response. Most of the SARS-CoV-2 subunit vaccines have focused on the spike protein or its fragments, such as the RBD [145]. Because of the activation of antibodies and contains HLA-restricted T-cell epitopes in the studies of MERS and SRAS-CoV, the $\mathrm{N}$ protein has also drawn some attention [146, 147].

NVX-CoV2373, produced by Novavax, is the leading candidate for the SARS-CoV-2 protein vaccine. This vaccine uses a saponin-based adjuvant to increment the adaptive immune responses to recombinant Ebola virus glycoprotein vaccines and MVA-based influenza vaccines [148].
This candidate uses a nanoparticle with the full-length spike protein that was capable of binding ACE2 receptors with high affinity. Instead of using the full-length spike protein, another candidate produced by Anhui Zhifei Longcom (NCT4464085) only utilizes the RBD of the spike protein. The University of Queensland in collaboration with GSK and Dynavax intends to use the Molecular Clamp technology to produce the neutralizing antibodies and use the adjuvant platform technology to enhance the vaccine response [132].

\section{DNA vaccine}

DNA-based vaccination approach is said to be the most revolutionary approach that encodes for the antigen [132]. DNA-based vaccination approach can increase the stability of the DNA molecule so that it can be used to construct a large number of mRNA molecules. Moreover, because the DNA vaccine is stable at room temperature, there is no need for a cold chain for this kind of vaccine. There are few DNA vaccines registered for human use, and the pipelines of DNA-based candidates for SRAS-CoV-2 can be divided into two ways: naked DNA plasmids and naked DNA plasmids plus electroporation [136].

INO-4800, produced by Inovio Pharmaceuticals, is a prophylactic DNA vaccine against COVID-19. The vaccine was created based on the synthesized SRAS-CoV-2 IgEspike sequence, and it was suggested that the vaccine can provide an effective immunity within a week after vaccination [149]. In the USA, there are more than three registered DNA vaccine candidates (https://clinicaltrials.gov/), but no additional information is available.

\section{RNA vaccine}

Although messenger RNA (mRNA) has not yet produced any registered vaccine in the past, the production of nucleic acid-based vaccine is often faster and cheaper than protein subunit vaccines [150], so that there have been six RNA vaccines for COVID-19 in the phase of clinical trials [134]. This kind of vaccine consists of viral antigenencoding mRNAs that can be translated by human cells to produce antigenic proteins and induce immunity. Similar to DNA vaccines, RNA vaccines are easy to modify the antigenic proteins, while they will not interact with hostcell DNA and thus no genomic integration risk exists. The biggest challenge of RNA vaccines is the propensity of mRNA to degrade. The vaccine is not as stable as the DNA vaccine and it must be stored and handled carefully. In addition, there is a potential risk of RNA-induced 
interferon response which is associated with inflammation and autoimmunity [151].

The mRNA-1273 vaccine produced by Moderna in collaboration with the National Ins of Allergy and Infectious Diseases is the leading RND vaccine candidate of SRAS-CoV-2. It encodes the spike-2 protein antigen and they substituted the amino acids at 986 and 987 with proline to stabilize the protein [131]. Several studies suggested that the mRNA-1273 vaccine is safe and effective in preventing COVID-19 [152, 153].

\section{Effectiveness of current vaccines}

As of November 2021, seven vaccines have been approved for full or emergency use by WHO: Pfizer-BioNTech, Oxford-AstraZeneca, Sinopharm BIBP, Moderna, Janssen, CoronaVac and Covaxin. Table 5 showed the efficacy and effectiveness of these vaccines from recent clinical trials and real world evidence, respectively. RNA-based vaccines have the best protection effect and the efficacy of viral vectored vaccines is not higher than $80 \%$. Due to the impact of variants, the effectiveness from real world studies all decreased compared to that from randomized clinical trials (RCT). It is showed that many variants of $\mathrm{CoV}$ can partially escape the immune barrier constructed by the vaccines. How different variants evade the vaccines can be seen in other place [154].

\section{The expected vaccination coverage of COVID-19}

After a development racing of COVID-19 vaccines, many candidates have been approved around the world. For instance, there are five types of vaccines approved by the National Food and Drug Administration in China, three for inactivated vaccines, one for recombinant subunit vaccine, and one for adenovirus vectored vaccine. To build up herd immunity as soon as possible, governments have tried their best to encourage people to be vaccinated. However, not all countries can afford the cost of vaccination for the whole population. What coverage threshold should each country reach is an important question for decision making. In other words, how many people in the world or a country will need to get a COVID-19 vaccine?

From the point of mathematic, as the meaning of reproductive number $(\mathrm{R})$, when each individual infects on average more than one, the scale of infected people will continue to grow exponentially; and when the R is less than one, the number of cases will gradually fall. Moreover, we
Table 5: Efficacy and effectiveness of COVID-19 vaccines approved for full or emergency use.

\begin{tabular}{|c|c|c|c|}
\hline \multirow[t]{2}{*}{ Vaccine } & \multirow[t]{2}{*}{ Type } & \multicolumn{2}{|c|}{$\begin{array}{l}\text { Effectiveness for symptomatic } \\
\text { infection }\end{array}$} \\
\hline & & RCT & Real world \\
\hline $\begin{array}{l}\text { Pfizer- } \\
\text { BioNTech }\end{array}$ & $\begin{array}{l}\text { RNA based } \\
\text { vaccine }\end{array}$ & $\begin{array}{r}91.3(89.0-93.2) \\
{[155]}\end{array}$ & $\begin{array}{l}83.0(78.0-87.0) \\
{[156]}\end{array}$ \\
\hline Moderna & $\begin{array}{l}\text { RNA based } \\
\text { vaccine }\end{array}$ & $\begin{array}{r}93.2(91.0-94.8) \\
{[157]}\end{array}$ & $\begin{array}{l}90.0(68.0-97.0) \\
{[158]}\end{array}$ \\
\hline $\begin{array}{l}\text { Oxford- } \\
\text { AstraZeneca }\end{array}$ & $\begin{array}{l}\text { Viral vectored } \\
\text { vaccine }\end{array}$ & $\begin{array}{r}74.0(65.3-80.5) \\
{[159]}\end{array}$ & $61.0(51.0-70.0)$ \\
\hline Janssen & $\begin{array}{l}\text { Viral vectored } \\
\text { vaccine }\end{array}$ & $\begin{array}{r}66.0(55.0-75.0) \\
{[160]}\end{array}$ & $N A^{a}$ \\
\hline $\begin{array}{l}\text { Sinopharm } \\
\text { BIBP }\end{array}$ & $\begin{array}{l}\text { Inactivated } \\
\text { virus vaccine }\end{array}$ & $\begin{array}{r}78.1(64.8-86.3) \\
{[161]}\end{array}$ & $N A^{a}$ \\
\hline CoronaVac & $\begin{array}{l}\text { Inactivated } \\
\text { virus vaccine }\end{array}$ & $\begin{array}{r}83.5(65.4-92.1) \\
{[162]}\end{array}$ & $65.9(65.2-66.6)$ \\
\hline Covaxin & $\begin{array}{l}\text { Inactivated } \\
\text { virus vaccine }\end{array}$ & $\begin{array}{r}77.8(65.2-86.4) \\
{[163]}\end{array}$ & $N A^{a}$ \\
\hline
\end{tabular}

${ }^{a}$ NA: not available.

can use $\mathrm{R}(\mathrm{t})$ to evaluate the effect of public health measures implemented by the government. On the other hand, we can also use $\mathrm{R}(\mathrm{t})$ to predict the extent of vaccines we at least use to control the pandemic and get herd immunity. If we refer to critical vaccine coverage $r^{\star}$, which is the proportion of randomly chosen individuals in the population that must be vaccinated to achieve $\mathrm{R}(\mathrm{t})<1$. If we have a vaccine that reduces transmission by a factor $\alpha$ then we can get the expected vaccination coverage rate:

$$
r^{*}=\frac{1}{\alpha}\left(1-\frac{1}{R_{t}}\right)
$$

In some textbooks, the $\mathrm{R}(\mathrm{t})$ will be replaced by $\mathrm{R}_{0}$ to represent the "getting back to normal" without any other immunity or control measures.

Obviously, $\alpha$ and $R$ are two important inputs, and the uncertainty of these numbers will dramatically influence the result. As we mentioned above, discrepancies in model specification, the scope of data, and even the population will make the reproductive number vary greatly. Therefore, we can use the pooled estimate of $R_{0}$ from meta-analysis to reduce this uncertainty.

What's more, the $\alpha$ varies across areas because different countries have chosen different vaccines. We calculated the critical coverages by assuming one vaccine used for the whole world in each case.

In the previous section, we get the pooled $R_{0}$ in the world is 2.88 (95\% CI: 2.70-3.06). If we use the minimum requirement of efficacy (70\%) listed by WHO, there must be at least 93.3\% (95\% CI: 89.9\%-96.2\%) people being 
Table 6: Expected coverage rate of Modera's vaccine for different continents.

\begin{tabular}{lrrr}
\hline & WHO & RCT & Real-world \\
\hline Asia & $83.1(74.1,89.9)$ & $62.4(55.7,67.6)$ & $64.6(57.7,70.0)$ \\
Europe & $97.5(92.9,100.0)$ & $73.2(69.8,76.2)$ & $75.8(72.3,78.9)$ \\
Africa & $96.2(79.9,100.0)$ & $72.2(60.0,79.5)$ & $74.8(62.1,82.3)$ \\
South & $92.9(62.1,100.0)$ & $69.8(46.7,80.1)$ & $72.3(48.3,83.0)$ \\
America & & & \\
North & $83.1(40.8,100.0)$ & $62.4(30.7,75.6)$ & $64.6(31.7,78.2)$ \\
America & & & \\
\hline
\end{tabular}

vaccinated. Specifically, the coverage rate in Asia needs to be $83.1 \%$ (95\% CI: $74.1 \%-89.9 \%$ ), while the expected coverage rate in Europe is the highest $(97.5 \%$ [95\% CI: $92.9 \%-100.0 \%])$.

According to the most recent RCT results of vaccines, if only Modera's vaccine were used, the coverage rate should range from $62.4 \%$ to $73.2 \%$. However, the evidence from real-world suggested that the critical coverage should be 64.6-75.8\%. This coverage means billions of dollars have to be spent and billions of people should be vaccinated. And the real efficacy of vaccines used in many countries was lower than $93.2 \%$, which means a much higher cost. Moreover, we can see a great discrepancy in coverage rates for different continents in Table 6 . No matter which effectiveness level, the coverage rates in Europe and Africa need to be $10 \%$ higher than in other regions.

It is a great challenge for all countries to produce such a large quantity of vaccines. A single country can't provide all the vaccines required worldwide. But currently, most countries are still not able to meet the needs by themselves. There is a big problem of vaccine resources distribution, and this is why WHO urgently calls for the equity of the COVID-19 vaccine.

\section{Equity in COVID-19 vaccine distribution}

\section{Inequities among countries}

Globally, to avoid the inequity in COVID-19 vaccine distribution among countries and to prevent a repeat of vaccine protectionism like the H1N1 scenario [86], the COVID-19 Vaccine Global Access (COVAX) Facility was established by WHO in April 2020 and was co-led by the Vaccine Alliance (Gavi), the Coalition for Epidemic Preparedness Innovations (CEPI). With lower prices for lowincome and middle-income countries, COVAX aims to provide all countries the opportunity to get at least $20 \%$ population vaccinated at the end of 2021. Under its vision, no country can be the first to vaccinate over $20 \%$ of its population if other countries cannot reach this rate [164].

Unfortunately, COVAX has not achieved its goal yet. Although the global administered coverage of the second dose has reached $15.5 \%$ in 9th Aug 2021, the United Kingdom, France, and the USA have vaccinated for more than $40 \%$ of its population, while the rates in lowand middle-income countries like Zambia, Sudan, and Nigeria are even lower than 10\% (https://ourworldindata. org/grapher/covid-vaccination-doses-per-capita). Because COVAX cannot make itself the only way to purchase vaccines, many high-income countries with smaller populations directly purchase vaccines from the developer instead of COVAX, which makes them host most of the vaccines in the world [165]. Moreover, insufficient funding has also prevented COVAX from providing an adequate share of vaccines to low- and middle-income countries that are more in need of them [166].

Besides the lack of a global vaccine stockpile, some researchers have also criticized the allocation strategies of COVAX $[167,168]$. At the first stage in COVAX's allocation structure, a proportional allocation strategy will be implemented for every country until all countries have reached the coverage goal. However, when high-income countries have broken the role on the distribution of vaccines, equity in population is no longer equal to fairness in need. Some additional allocation models based on ethical equity have been proposed as complements of COVAX, such as the fair priority model (FPM) [168] and multi-value ethical framework (MEF) [86].

\section{Inequities among populations}

When limited vaccines are available in the early stage of the vaccination program, policymakers have to decide on who should be vaccinated first. Accounting for both health and economic benefits, all countries face a multicriteria decision problem. As recommended by WHO, many countries have given priority to key workers, clinically vulnerable groups, and elderly groups under the structure of the Strategic Advisory Group of Experts on Immunization (SAGE) [169, 170]. However, pregnant women, an important vulnerable group, were excluded from the recruitment lists of most of the global clinical trials [171]. Without evidence about safety and efficacy during pregnancy, pregnant women have fallen into a perpetuated cycle of exclusion [172]. When pregnant women are not 
considered in early efforts of vaccine development, they are in turn excluded from generations of evidence, and they are excluded from vaccination programs. Ignoring pregnant women, who have equivalent or even worse outcomes compared with non-pregnant groups, are harmful to the global COVID-19 disease burden and are unjust in the progress of global immunization of COVID-19 vaccines.

Many researchers have advocated the inclusion of pregnant groups [172-174], and the Pregnancy Research Ethics for Vaccines, Epidemics, and New Technologies (PREVENT) Working Group even issued 22 recommendations to promote equity for pregnant women in vaccine development and response [175]. Although pregnant women were not in most of the cohorts of trials, some pregnancies occurred across the trials of three vaccines previously approved in the UK [176]. The data showed no significant detrimental effect of vaccination on pregnancy. Thus, the United Kingdom, the United States, and European Union all recommended pregnant people to be vaccinated if the benefits outweigh the potential risks. Moreover, Shimabukuro et al. [177] provide more scientific evidence about vaccine safety in pregnant persons. Based on a vaccination health checker surveillance system data of 35,691 participants in the USA, they find no obvious safety signals among pregnant persons who received mRNA COVID-19 vaccines. Although it is said that more longitudinal follow-ups with large numbers of women vaccinated earlier in pregnancy are needed, at least the mRNA vaccines of COVID-19 are most likely adequate for the pregnant group. As mentioned in the previous section, mRNA vaccines are not very stable and have high requirements for the cold chain. Due to the high cost of cold chain transportation, there is no well-operated cold chain network in many low-income countries. Even if mRNA vaccines are completely safe and effective for pregnant women, the inequity of pregnant women vaccination still exists in low-income countries.

Racial inequities in vaccination also persist. Take the United States as an example, from the latest data on COVID-19 vaccinations by race, nearly two-thirds of people who had received at least one dose of the vaccine were White (58\%), and only $10 \%$ were Black and $6 \%$ for Asian [178]. Black people have only received a small share of vaccination, whereas more than half of cases and deaths were made up of them. Despite the hesitancy for the vaccine, a long time of medical racism and misinformation has caused the unfairness of vaccination for Black [179]. CDC in the USA has made many efforts to ensure that Black and other minorities have fair and just access to COVID-19 vaccination. But as the mantra of the COVID-19 pandemic, "No one is safe until everyone is safe" [180], the efforts of filling the gap in the vaccination of minorities are far from enough.

\section{Conclusion}

COVID-19 has raised serious concerns globally. As of April 4, 2021, at least 130 million cases and 2 million deaths associated with SARS-Cov-2 have been recorded worldwide. Confirmed to occur during close person-to-person contact, the major transmission route of COVID-19 is airborne transmission. Aerosol particles consisting of respiratory droplets can be a direct dispersion of the SARS-CoV-2, and ambient aerosols can be the indirect ones. Thus it is necessary to implement social distancing interventions and reduce aerosol pollution levels to bring this epidemic under control. There is no determined proof for faecal-oral, vertical, and foodborne transmission, more evidence is required to accurately reveal the infectivity and pathogenesis of these transmission routes of SARS-CoV-2. Curbing COVID-19 infections primarily demands efforts from every country. It is noted that in the absence of drastic action, even the best health systems can be inefficient. Comprehensive interventions (suspension of gathering activities and entertainment, case isolation, tracing and screening of contacts of confirmed cases, and screening of people's temperature in public places) and lockdowns would be effective for reducing COVID-19 transmission and avoiding future outbreaks of SARS-CoV-2. It is necessary for all the countries to rethink the use of more tailored measures if COVID-19 is to be with us for years to come. Besides, countries and regions worldwide must strengthen coordination and cooperation to control the epidemic.

The global effort to develop safe and effective COVID-19 vaccines has yielded remarkable results. In the race of COVID-19 vaccine development, six strategies were implemented to create effective candidates to control the SARS-CoV-2 replication at the individual level. Many of these candidates were based on the spike protein or its subdomain of the SARS-CoV-2, whereas variants of $\mathrm{CoV}$ can partially evade current vaccines. Thus, the critical coverage rate would be higher and the development of new vaccines is always on the road. The vaccination program of COVID-19 is also not for a single country or area. Vaccination to achieve control of the pandemic with no public health measures still requires huge resources, even if the best vaccine candidate is used for everyone. Great equity problems exist in the distribution of vaccines among countries and people groups. Although we have made some efforts to provide low- and middle-income countries 
and vulnerable groups more opportunities of vaccination, we need to carry out more international cooperation in COVID-19 vaccine research and development so that each country can afford the burden of vaccination and balance the shares of vaccines among groups in its own country. Before herd immunity is reached to block mutations, the use of comprehensive interventions and vaccines together is essential for the most effective control of COVID-19.

Acknowledgments: The views expressed in the submitted article are of those of the authors themselves and not an official position of their affiliated institutions and organizations.

Research funding: The research is supported by funding from the National Natural Science Foundation of China (81973150).

Author contributions: All authors have accepted responsibility for the entire content of this manuscript and approved its submission.

Competing interests: Authors state no conflict of interest. Informed consent: Not applicable.

Ethical approval: Not applicable.

\section{References}

1. Peeri NC, Shrestha N, Rahman MS, Zaki R, Tan Z, Bibi S, et al. The SARS, MERS and novel coronavirus (COVID-19) epidemics, the newest and biggest global health threats: what lessons have we learned? Int J Epidemiol 2020;49:717-26.

2. International Expert Meeting on the Treatment of SbTCM, the Integration of Traditional Chinese Medicine with Western M. SARS: clinical trials on treatment using a combination of traditional Chinese medicine and Western medicine: report of the WHO International Expert Meeting to review and analyse clinical reports on combination treatment for SARS, 8-10 October 2003. Beijing, People's Republic of China. In. Geneva: World Health Organization; 2004.

3. WHO. Middle East respiratory syndrome coronavirus (MERS-CoV). Available from: https://www.who.int/healthtopics/middle-east-respiratory-syndrome-coronavirusmers\#tab=tab_1 [Accessed 4 Apr 2021].

4. Al-Omari A, Rabaan AA, Salih S, Al-Tawfiq JA, Memish ZA. MERS coronavirus outbreak: implications for emerging viral infections. Diagn Microbiol Infect Dis 2019;93:265-85.

5. Zhu N, Zhang D, Wang W, Li X, Yang B, Song J, et al. A novel coronavirus from patients with pneumonia in China, 2019. N Engl J Med 2020;382:727-33.

6. Cucinotta D, Vanelli M. WHO declares COVID-19 a pandemic. Acta bio-medica: Atenei Parmensis. 2020;91:157-60.

7. WHO. WHO coronavirus (COVID-19) dashboard. Available from: https://covid19.who.int/ [Accessed 4 Apr 2021].

8. Aghaali M, Kolifarhood G, Nikbakht R, Saadati HM, Hashemi Nazari SS. Estimation of the serial interval and basic reproduction number of COVID-19 in Qom, Iran, and three other countries: a data-driven analysis in the early phase of the outbreak. Transboundary Emerg Dis 2020;67: 2860-8.

9. Alimohamadi Y, Taghdir M, Sepandi M. Estimate of the basic reproduction number for COVID-19: a systematic review and meta-analysis. J Prev Med Public Health Yebang Uihakhoe chi 2020;53:151-7.

10. Billah MA, Miah MM, Khan MN. Reproductive number of coronavirus: a systematic review and meta-analysis based on global level evidence. PLoS One 2020;15:e0242128.

11. Heesterbeek JA, Roberts MG. The type-reproduction number T in models for infectious disease control. Math Biosci 2007;206: 3-10.

12. Heffernan JM, Smith RJ, Wahl LM. Perspectives on the basic reproductive ratio. J $R$ Soc Interface 2005;2:281-93.

13. He W, Yi GY, Zhu Y. Estimation of the basic reproduction number, average incubation time, asymptomatic infection rate, and case fatality rate for COVID-19: meta-analysis and sensitivity analysis. J Med Virol 2020;92:2543-50.

14. Hussein M, Toraih E, Elshazli R, Fawzy M, Houghton A, Tatum D, et al. Meta-analysis on serial intervals and reproductive rates for SARS-CoV-2. Ann Surg 2021;273:416-23.

15. Yu C-J, Wang Z-X, Xu Y, Hu M-X, Chen K, Qin G. Assessment of basic reproductive number for COVID-19 at global level: a metaanalysis. Medicine (Baltimore) 2021;100:e25837.

16. Chan FW, Kok KH, Zhu Z, Chu H, Yuen KY. Genomic characterization of the 2019 novel human-pathogenic coronavirus isolated from a patient with atypical pneumonia after visiting Wuhan. Emerg Microb Infect 2020;9:221-36.

17. Rabaa NAA, Al-Ahmed SH, Haque S, Sah R, Rodriguez-Morales AJJ. Liimrpde, epidemiologia, diagnostica, clinica e terapia delle patologie infettive. SARS-CoV-2, SARS-CoV, and MERS-CoV: a comparative overview. Infezioni Med Le 2020;28:174-84.

18. Xie M, Chen Q. Insight into 2019 novel coronavirus - an updated interim review and lessons from SARS-CoV and MERS-CoV. Int J Infect Dis 2020;94:119-24.

19. Beniac DR, Andonov A, Grudeski E, Booth TF. Architecture of the SARS coronavirus prefusion spike. Nat Struct Mol Biol 2006;13: 751-2.

20. Wu A, Peng Y, Huang B, Ding X, Jiang TJCH. Genome composition and divergence of the novel coronavirus (2019-nCoV) originating in China. Cell Host Microbe 2020;27:325-28.

21. Xu X, Chen P, Wang J, Feng J, Zhou H. Evolution of the novel coronavirus from the ongoing Wuhan outbreak and modeling of its spike protein for risk of human transmission. Science China 2020;v.63:143-6.

22. Wrapp D, Wang N, Corbett KS, Goldsmith JA, Hsieh C-L, Abiona O, et al. Cryo-EM structure of the 2019-nCoV spike in the prefusion conformation. Science 2020;367:1260-3.

23. Ortega JT, Serrano ML, Pujol FH, Rangel HR. Role of changes in SARS-CoV-2 spike protein in the interaction with the human ACE2 receptor: an in silico analysis. EXCLI J 2020;19: 410-7.

24. Korber B, Fischer WM, Gnanakaran S, Yoon H, Theiler J, Abfalterer W, et al. Tracking changes in SARS-CoV-2 spike: evidence that D614G increases infectivity of the COVID-19 virus. Cell 2020;182:812-27.e19.

25. Mercatelli D, Giorgi FM. Geographic and genomic distribution of SARS-CoV-2 mutations. Front Microbiol 2020;11:1800. 
26. Prevention UCfDCa. SARS-CoV-2 variant classifications and definitions; 2021. Updated Dec 2021. Available from: https://www.cdc.gov/coronavirus/2019-ncov/variants/ variant-info.html [Accessed 3 Dec 2021].

27. Faria NR, Mellan TA, Whittaker C, Claro IM, Candido DS, Mishra S, et al. Genomics and epidemiology of the P.1 SARS-CoV-2 lineage in Manaus, Brazil. Science (New York, NY) 2021;372:815-21.

28. Oliveira MM, Schemberger MO, Suzukawa AA, Riediger IN, do Carmo Debur M, Becker G, et al. Re-emergence of Gamma-likeII and emergence of Gamma-S:E661D SARS-CoV-2 lineages in the south of Brazil after the 2021 outbreak. Virol J 2021;18:222.

29. Li B, Deng A, Li K, Hu Y, Li Z, Xiong Q, et al. Viral infection and transmission in a large well-traced outbreak caused by the Delta SARS-CoV-2 variant. medRxiv 2021. https://doi.org/10.1101/ 2021.07.07.21260122.

30. WHO. Classification of Omicron (B.1.1.529): SARS-CoV-2 variant of concern. 2021. Updated Nov 2021. Available from: https://www.who.int/news/item/26-11-2021-classificationof-omicron-(b.1.1.529)-sars-cov-2-variant-of-concern [Accessed 3 Dec 2021].

31. WHO. Update on Omicron. 2021. Updated Nov 2021. Available from: https://www.who.int/news/item/28-11-2021-update-onomicron [Accessed 3 Dec 2021].

32. Fehr AR, Perlman S. Coronaviruses: an overview of their replication and pathogenesis. Methods Mol Biol 2015;1282:1-23.

33. Gorbalenya AE, Enjuanes L, Ziebuhr J, Snijder EJ. Nidovirales: evolving the largest RNA virus genome. Virus Res 2006;117: 17-37.

34. Wan Y, Shang J, Graham R, Baric RS, Li F. Receptor recognition by the novel coronavirus from Wuhan: an analysis based on decade-long structural studies of SARS coronavirus. J Virol 2020;94:e00127-20.

35. Cunningham A. COVID-19: the wildlife facts. 2020. Available from: https://www.zsl.org/blogs/science/covid-19-thewildlife-facts [Accessed 16 Apr 2020].

36. Takekawa JY, Prosser DJ, Newman SH, Muzaffar SB, Hill NJ, Yan B, et al. Victims and vectors: highly pathogenic avian influenza H5N1 and the ecology of wild birds. Avian Biol Res 2010;3:51-73.

37. Perveen N, Muzaffar SB, Al-Deeb MA. Exploring human-animal host interactions and emergence of COVID-19: evolutionary and ecological dynamics. Saudi J Biol Sci 2021;28:1417-25.

38. Huang C, Wang Y, Li X, Ren L, Zhao J, Hu Y, et al. Clinical features of patients infected with 2019 novel coronavirus in Wuhan, China. Lancet 2020;395:497-506.

39. Lelieveld J, Helleis F, Borrmann S, Cheng Y, Drewnick F, Haug G, et al. Model calculations of aerosol transmission and infection risk of COVID-19 in indoor environments. Int J Environ Res Publ Health 2020;17:8114.

40. Asadi S, Bouvier N, Wexler AS, Ristenpart WD. The coronavirus pandemic and aerosols: does COVID-19 transmit via expiratory particles? Aerosol Sci Technol 2020;0:1-4.

41. Cao Y, Shao L, Jones T, Oliveira MLS, Ge S, Feng X, et al. Multiple relationships between aerosol and COVID-19: a framework for global studies. Gondwana Res 2021;93:243-51.

42. April Si X, Talaat M, Xi J. SARS COV-2 virus-laden droplets coughed from deep lungs: numerical quantification in a singlepath whole respiratory tract geometry. Phys Fluids (1994) 2021; 33:023306.
43. Zuo T, Liu Q, Zhang F, Lui GC, Tso EY, Yeoh YK, et al. Depicting SARS-CoV-2 faecal viral activity in association with gut microbiota composition in patients with COVID-19. Gut 2021;70: 276-84.

44. Zheng S, Fan J, Yu F, Feng B, Lou B, Zou Q, et al. Viral load dynamics and disease severity in patients infected with SARS-CoV-2 in Zhejiang province, China, January-March 2020: retrospective cohort study. BMJ 2020;369:m1443.

45. Wu Y, Guo C, Tang L, Hong Z, Zhou J, Dong X, et al. Prolonged presence of SARS-CoV-2 viral RNA in faecal samples. Lancet Gastroenterol Hepatol 2020;5:434-5.

46. Xing YH, Ni W, Wu Q, Li WJ, Li GJ, Wang WD, et al. Prolonged viral shedding in feces of pediatric patients with coronavirus disease 2019. J Microbiol Immunol Infect 2020;53:473-80.

47. Guo M, Tao W, Flavell RA, Zhu S. Potential intestinal infection and faecal-oral transmission of SARS- CoV-2. Nat Rev Gastroenterol Hepatol 2021;18:269-83.

48. Kotlyar AM, Grechukhina O, Chen A, Popkhadze S, Grimshaw A, Tal O, et al. Vertical transmission of coronavirus disease 2019: a systematic review and meta-analysis. Am J Obstet Gynecol 2021; 224:35-53.e3.

49. Kirtsman M, Diambomba Y, Poutanen SM, Malinowski AK, Vlachodimitropoulou E, Parks WT, et al. Probable congenital SARS-CoV-2 infection in a neonate born to a woman with active SARS-CoV-2 infection. Cmaj 2020;192:E647-50.

50. Wu Y, Liu C, Dong L, Zhang C, Chen Y, Liu J, et al. Coronavirus disease 2019 among pregnant Chinese women: case series data on the safety of vaginal birth and breastfeeding. BJOG 2020;127: 1109-15.

51. Buonsenso D, Costa S, Sanguinetti M, Cattani P, Posteraro B, Marchetti $S$, et al. Neonatal late onset infection with severe acute respiratory syndrome coronavirus 2. Am J Perinatol 2020; 37:869-72.

52. Centeno-Tablante E, Medina-Rivera M, Finkelstein JL, RaycoSolon P, Garcia-Casal MN, Rogers L, et al. Transmission of SARS-CoV-2 through breast milk and breastfeeding: a living systematic review. Ann N Y Acad Sci 2021;1484:32-54.

53. Godoy MG, Kibenge MJT, Kibenge FSB. SARS-CoV-2 transmission via aquatic food animal species or their products: a review. Aquaculture 2021;536:736460.

54. EFSA. Coronavirus: no evidence that food is a source or transmission route. 2020. Available from: http://www.efsa. europa.eu/en/news/coronavirus-no-evidence-food-source-ortransmission-route [Accessed 21 June 2020].

55. Han J, Zhang X, He S, Jia P. Can the coronavirus disease be transmitted from food? A review of evidence, risks, policies and knowledge gaps. Environ Chem Lett 2020:1-12. https://doi.org/10.1007/s10311-020-01101-x.

56. Bondad-Reantaso MG, MacKinnon B, Bin H, Huang J, TangNelson K, Surachetpong W, et al. Viewpoint: SARS-CoV-2 (the cause of COVID-19 in humans) is not known to infect aquatic food animals nor contaminate their products. Asian Fish Sci 2020;33:74-8.

57. CDC. Update: COVID-19 among workers in meat and poultry processing facilities-United States, April-May 2020; 2020. Available from: https://www.cdc.gov/mmwr/volumes/69/wr/ mm6927e2.htm [Accessed 2 Sept 2020].

58. Chin AWH, Chu JTS, Perera MRA, Hui KPY, Yen H-L, Chan MCW, et al. Stability of SARS-CoV-2 in different environmental conditions. Lancet Microbe 2020;1:e10. 
59. Fisher D, Reilly A, Kang E, Zheng A, Cook A, Anderson D. Seeding of outbreaks of COVID-19 by contaminated fresh and frozen food. bioRxiv 2021. https://doi.org/10.1101/2020.08.17. 255166.

60. Liu Y, Gayle AA, Wilder-Smith A, Rocklov J. The reproductive number of COVID-19 is higher compared to SARS coronavirus. J Trav Med 2020;27:taaa021.

61. Delamater PL, Street EJ, Leslie TF, Yang YT, Jacobsen KH. Complexity of the basic reproduction number $(R(0))$. Emerg Infect Dis 2019;25:1-4.

62. Lim J-S, Cho S-I, Ryu S, Pak S-I. Interpretation of the basic and effective reproduction number. J Prevent Med Public Health Yebang Uihakhoe chi 2020;53:405-8.

63. Ryu S, Chun BC. An interim review of the epidemiological characteristics of 2019 novel coronavirus. Epidemiol Health 2020;42:e2020006.

64. Ridenhour B, Kowalik JM, Shay DK. Unraveling R0: considerations for public health applications. Am J Publ Health 2014;104:e32-41.

65. Li J, Blakeley D, Smith RJ. The failure of R0. Comput Math Methods Med 2011;2011:527610.

66. Tang B, Wang X, Li Q, Bragazzi NL, Tang S, Xiao Y, et al. Estimation of the transmission risk of the 2019-nCoV and its implication for public health interventions. J Clin Med 2020;9:462.

67. Zhang S, Diao M, Yu W, Pei L, Lin Z, Chen D. Estimation of the reproductive number of novel coronavirus (COVID-19) and the probable outbreak size on the Diamond Princess cruise ship: a data-driven analysis. Int J Infect Dis 2020;93:201-4.

68. Liu T, Hu J, Xiao J, He G, Kang M, Rong Z, et al. Time-varying transmission dynamics of novel coronavirus pneumonia in China. bioRxiv 2020. https://doi.org/10.1101/2020.01.25. 919787.

69. Shao N, Cheng J, Chen W. The reproductive number $R_{0}$ of COVID-19 based on estimate of a statistical time delay dynamical system. medRxiv 2020. https://doi.org/10.1101/ 2020.02.17.20023747.

70. Sahafizadeh E, Sartoli S. Epidemic curve and reproduction number of COVID-19 in Iran. J Travel Med 2020;27:taaa077.

71. Ghanei Gheshlagh R, Aslani M, Shabani F, Dalvand S, Parizad N. Prevalence of needlestick and sharps injuries in the healthcare workers of Iranian hospitals: an updated meta-analysis. Environ Health Prev Med 2018;23:44.

72. Hayashino Y, Noguchi Y, Fukui T. Systematic evaluation and comparison of statistical tests for publication bias. J Epidemiol 2005;15:235-43.

73. Duval S, Tweedie R. A nonparametric "trim and fill" method of accounting for publication bias in meta-analysis. J Am Stat Assoc 2000;95:89-98.

74. Team RC. A language and environment for statistical computing. Vienna, Austria: R Foundation for Statistical Computing; 2020. Available from: https://www.r-project.org/ [Accessed $10 \mathrm{Apr}$ 2021].

75. Li R, Pei S, Chen B, Song Y, Zhang T, Yang W, et al. Substantial undocumented infection facilitates the rapid dissemination of novel coronavirus (SARS-CoV-2). Science 2020;368:489-93.

76. Muniz-Rodriguez K, Fung IC, Ferdosi SR, Ofori SK, Lee Y, Tariq A, et al. Severe acute respiratory syndrome coronavirus 2 transmission potential, Iran, 2020. Emerg Infect Dis 2020;26: 1915-7.
77. Munayco CV, Tariq A, Rothenberg R, Soto-Cabezas GG, Reyes MF, Valle A, et al. Early transmission dynamics of COVID-19 in a southern hemisphere setting: Lima-Peru: February 29(th)-March 30(th), 2020. Infect Dis Model 2020;5:338-45.

78. Manevski D, Ružić Gorenjec N, Kejžar N, Blagus R. Modeling COVID-19 pandemic using Bayesian analysis with application to Slovene data. Math Biosci 2020;329:108466.

79. Adekunle Al, Adegboye OA, Gayawan E, McBryde ES. Is Nigeria really on top of COVID-19? Message from effective reproduction number. Epidemiol Infect 2020;148:e166.

80. Taha Rouabah M, Tounsi A, Eddine Belaloui N. A mathematical epidemic model using genetic fitting algorithm with crossvalidation and application to early dynamics of COVID-19 in Algeria; 2020. arXiv:2005.13516 [Accessed 01 May 2020].

81. Talmoudi K, Safer M, Letaief H, Hchaichi A, Harizi C, Dhaouadi S, et al. Estimating transmission dynamics and serial interval of the first wave of COVID-19 infections under different control measures: a statistical analysis in Tunisia from February 29 to May 5, 2020. BMC Infect Dis 2020;20:914.

82. Xu C, Dong YQ, Yu XY, Wang HW, Tsamlag L, Zhang SX, et al. Estimation of reproduction numbers of COVID-19 in typical countries and epidemic trends under different prevention and control scenarios. Front Med 2020;14:613-22.

83. Kobayashi G, Sugasawa S, Tamae H, Ozu T. Predicting intervention effect for COVID-19 in Japan: state space modeling approach. Biosci Trends 2020;14:174-81.

84. Lei H, Wu X, Wang X, Xu M, Xie Y, Du X, et al. Different transmission dynamics of COVID-19 and influenza suggest the relative efficiency of isolation/quarantine and social distancing against COVID-19 in China. Clin Infect Dis 2020:ciaa1584.

85. Gupta M, Mohanta SS, Rao A, Parameswaran GG, Agarwal M, Arora M, et al. Transmission dynamics of the COVID-19 epidemic in India and modeling optimal lockdown exit strategies. Int J Infect Dis 2021;103:579-89.

86. Liu QH, Bento Al, Yang K, Zhang H, Yang X, Merler S, et al. The COVID-19 outbreak in Sichuan, China: epidemiology and impact of interventions. PLoS Comput Biol 2020;16:e1008467.

87. Sardar T, Nadim SS, Rana S, Chattopadhyay J. Assessment of lockdown effect in some states and overall India: a predictive mathematical study on COVID-19 outbreak. Chaos Solit Fractals 2020;139:110078.

88. Saurabh S, Verma MK, Gautam V, Kumar N, Goel AD, Gupta MK, et al. Transmission dynamics of the COVID-19 epidemic at the district level in India: prospective observational study. JMIR Public Health Surveill 2020;6:e22678.

89. Sugishita Y, Kurita J, Sugawara T, Ohkusa Y. Effects of voluntary event cancellation and school closure as countermeasures against COVID-19 outbreak in Japan. PLoS One 2020;15: e0239455.

90. Kuniya T. Evaluation of the effect of the state of emergency for the first wave of COVID-19 in Japan. Infect Dis Model 2020;5: $580-7$.

91. Hao X, Cheng S, Wu D, Wu T, Lin X, Wang C. Reconstruction of the full transmission dynamics of COVID-19 in Wuhan. Nature 2020; 584:420-4.

92. Zhang XS, Vynnycky E, Charlett A, De Angelis D, Chen Z, Liu W. Transmission dynamics and control measures of COVID-19 outbreak in China: a modelling study. Sci Rep 2021; 11:2652. 
93. Wangping J, Ke H, Yang S, Wenzhe C, Shengshu W, Shanshan Y, et al. Extended SIR prediction of the epidemics trend of COVID-19 in Italy and compared with Hunan, China. Front Med (Lausanne) 2020;7:169.

94. Linka K, Peirlinck M, Kuhl E. The reproduction number of COVID-19 and its correlation with public health interventions. Comput Mech 2020:1-16. https://doi.org/10.1101/2020.05.01. 20088047.

95. Di Domenico L, Pullano G, Sabbatini CE, Boëlle PY, Colizza V. Impact of lockdown on COVID-19 epidemic in île-de-France and possible exit strategies. BMC Med 2020;18:240.

96. Lemaitre JC, Perez-Saez J, Azman AS, Rinaldo A, Fellay J. Assessing the impact of non-pharmaceutical interventions on SARS-CoV-2 transmission in Switzerland. Swiss Med Wkly 2020; 150:W20295.

97. Mamon G. Regional analysis of COVID-19 in France from fit of hospital data with different evolutionary models. arXiv 2020; arXiv:2005.06552.

98. Flaxman S, Mishra S, Gandy A, Unwin HJT, Mellan TA, Coupland $\mathrm{H}$, et al. Estimating the effects of non-pharmaceutical interventions on COVID-19 in Europe. Nature 2020;584:257-61.

99. Sypsa V, Roussos S, Paraskevis D, Lytras T, Tsiodras S, Hatzakis A. Effects of social distancing measures during the first epidemic wave of severe acute respiratory syndrome infection, Greece. Emerg Infect Dis 2021;27:452-62.

100. Childs ML, Kain MP, Kirk D, Harris M, Couper L, Nova N, et al. The impact of long-term non-pharmaceutical interventions on COVID-19 epidemic dynamics and control: the value and limitations of early models. Proceedings of the Royal Society B 2021;288t:0811.

101. Worden L, Wannier R, Blumberg S, Ge AY, Rutherford GW, Porco TC. Estimation of effects of contact tracing and mask adoption on COVID-19 transmission in San Francisco: a modeling study. medRxiv 2020. https://doi.org/10.1101/2020. 06.09.20125831. 32577672.

102. Cruz PAD, Crema-Cruz LC, Campos FS. Modeling transmission dynamics of severe acute respiratory syndrome coronavirus 2 in São Paulo, Brazil. Rev Soc Bras Med Trop 2021;54:e05532020.

103. Tariq A, Undurraga EA, Laborde CC, Vogt-Geisse K, Luo R, Rothenberg $R$, et al. Transmission dynamics and control of COVID-19 in Chile, March-October, 2020. PLoS Neglected Trop Dis 2021;15:e0009070.

104. Arroyo-Marioli F, Bullano F, Kucinskas S, Rondón-Moreno C. Tracking R of COVID-19: a new real-time estimation using the Kalman filter. PLoS One 2021;16:1-16.

105. Zhou T, Liu Q, Yang Z, Liao J, Yang K, Bai W, et al. Preliminary prediction of the basic reproduction number of the Wuhan novel coronavirus 2019-nCoV. J Evid Base Med 2020;13:3-7.

106. Kwok KO, Tang A, Wei VWI, Park WH, Yeoh EK, Riley S. Epidemic models of contact tracing: systematic review of transmission studies of severe acute respiratory syndrome and Middle East respiratory syndrome. Comput Struct Biotechnol J 2019;17: 186-94.

107. Read J, Bridgen JRE, Cummings DAT, Ho A, Jewell C. Novel coronavirus 2019-nCoV: early estimation of epidemiological parameters and epidemic predictions. Philos Trans R Soc Lond B Biol Sci 2021;376:20200265.

108. Choi S, Jung E, Choi BY, Hur YJ, Ki M. High reproduction number of Middle East respiratory syndrome coronavirus in nosocomial outbreaks: mathematical modelling in Saudi Arabia and South Korea. J Hosp Infect 2018;99:162-8.

109. Chowell G, Castillo-Chavez C, Fenimore PW, Kribs-Zaleta CM, Arriola L, Hyman JM. Model parameters and outbreak control for SARS. Emerg Infect Dis 2004;10:1258-63.

110. Dietz K. The estimation of the basic reproduction number for infectious diseases. Stat Methods Med Res 1993;2:23-41.

111. Al-Raeei $M$. The basic reproduction number of the new coronavirus pandemic with mortality for India, the Syrian Arab Republic, the United States, Yemen, China, France, Nigeria and Russia with different rate of cases. Clin Epidemiol Global Health 2021;9:147-9.

112. Erol A. Are the emerging SARS-COV-2 mutations friend or foe? Immunol Lett 2021;230:63-4.

113. Dos Santos WG. Impact of virus genetic variability and host immunity for the success of COVID-19 vaccines. Biomed Pharmacother Biomedecine \& pharmacotherapie 2021;136: 111272.

114. Hou YJ, Chiba S, Halfmann P, Ehre C, Kuroda M, Dinnon KH 3rd, et al. SARS-CoV-2 D614G variant exhibits efficient replication ex vivo and transmission in vivo. Science 2020;370:1464-8.

115. Ives AR, Bozzuto C. Estimating and explaining the spread of COVID-19 at the county level in the USA. Commun Biol 2021; $4: 60$.

116. You C, Deng Y, Hu W, Sun J, Lin Q, Zhou F, et al. Estimation of the time-varying reproduction number of COVID-19 outbreak in China. Int J Hyg Environ Health 2020;228:113555.

117. Nikbakht R, Baneshi MR, Bahrampour A, Hosseinnataj A. Comparison of methods to estimate basic reproduction number (R (0)) of influenza, using Canada 2009 and 2017-18 A (H1N1) data. J Res Med Sci 2019;24:67.

118. Liu T, Hu J, Kang M, Lin L, Zhong H, Xiao J, et al. Transmission dynamics of 2019 novel coronavirus (2019-nCoV). bioRxiv 2020 https://doi.org/10.1101/2020.01.25.919787.

119. Hao T. Infection dynamics of coronavirus disease 2019 (Covid19) modeled with the integration of the eyring's rate process theory and free volume concept. medRxiv 2020. https://doi.org/ 10.1101/2020.02.26.20028571.

120. Wang K, Zhang X, Jin Z, Ma H, Teng Z, Wang L. Modeling and analysis of the transmission of Echinococcosis with application to Xinjiang Uygur Autonomous region of China. J Theor Biol 2013; 333:78-90.

121. Wallinga J, Teunis P. Different epidemic curves for severe acute respiratory syndrome reveal similar impacts of control measures. Am J Epidemiol 2004;160:509-16.

122. Cauchemez S, Boëlle PY, Thomas G, Valleron AJ. Estimating in real time the efficacy of measures to control emerging communicable diseases. Am J Epidemiol 2006;164:591-7.

123. Zhang Y, Quigley A, Wang Q, MacIntyre CR. Non-pharmaceutical interventions during the roll out of COVID-19 vaccines. BMJ 2021; 375: $\mathrm{n} 2314$

124. OECD. Flattening the COVID-19 peak: containment and mitigation policies. Available from: https://www.oecd.org/ coronavirus/policy-responses/flattening-the-covid-19-peakcontainment-and-mitigation-policies-e96a4226/ [Accessed 5 Dec 2021].

125. Migone AR. The influence of national policy characteristics on COVID-19 containment policies: a comparative analysis. Policy Des Pract 2020;3:259-76. 
126. Ren X. Pandemic and lockdown: a territorial approach to COVID-19 in China, Italy and the United States. Eurasian Geogr Econ 2020;61:423-34.

127. Davies NG, Klepac P, Liu Y, Prem K, Jit M, Eggo RM. Agedependent effects in the transmission and control of COVID-19 epidemics. Nat Med 2020;26:1205-11.

128. News A. Japan declares state of emergency, ramping up virus battle; 2020. Updated April 7, 2020. Available from: https://apnews.com/article/ b4c774ef3b14b923e5be6acd01613487 [Accessed 11 Apr 2021].

129. WHO. WHO target product profiles for COVID-19 vaccines: version 3. WHO; 2020:1-6 pp. https://cdn.who.int/media/ docs/default-source/blue-print/who-target-product-profilesfor-covid-19-vaccines.pdf?sfvrsn=1d5da7ca_5\&download=true [Accessed 11 Apr 2021].

130. Administration USFaD. Development and Licensure of vaccines to prevent COVID-19: guidance for industry; 2020. Available from: https://public-inspection.federalregister.gov/202114637.pdf [Accessed 21 June 2021].

131. Li YD, Chi WY, Su JH, Ferrall L, Hung CF, Wu TC. Coronavirus vaccine development: from SARS and MERS to COVID-19. J Biomed Sci 2020;27:104.

132. Kaur SP, Gupta V. COVID-19 Vaccine: a comprehensive status report. Virus Res 2020;288:198114.

133. Cohen J. Leader of U.S. vaccine push says, he'll quit if politics trumps science. In: Science; 2020.

134. WHO. Draft landscape of COVID-19 candidate vaccines. Geneva: World Health Organization;2020.

135. Stauft CB, Chen Y, Coleman JR, Boltz D, Mueller S. Liveattenuated $\mathrm{H} 1 \mathrm{~N} 1$ influenza vaccine candidate displays potent efficacy in mice and ferrets. PLoS One 2019;14:e0223784.

136. Forni G, Mantovani A, Covid-19 Commission of Accademia Nazionale dei Lincei R. COVID-19 vaccines: where we stand and challenges ahead. Cell Death Differ 2021;28:626-39.

137. Zhang Y, Zeng G, Pan H, Li C, Kan B, Hu Y, et al. Safety, tolerability, and immunogenicity of an inactivated SARS-CoV-2 vaccine in healthy adults aged 18-59 years: a randomised, double-blind, placebo-controlled, phase $1 / 2$ clinical trial. Lancet Infectious Disease 2020;21:181-92.

138. Izda V, Jeffries MA, Sawalha AH. COVID-19: a review of therapeutic strategies and vaccine candidates. Clin Immunol 2021;222:108634.

139. Kim JH, Marks F, Clemens JD. Looking beyond COVID-19 vaccine phase 3 trials. Nat Med 2021;27:205-11.

140. Gao Q, Bao L, Mao H, Wang L, Xu K, Yang M, et al. Development of an inactivated vaccine candidate for SARS-CoV-2. Science 2020; 369:eabc1932.

141. Ura T, Okuda K, Shimada M. Developments in viral vector-based vaccines. Vaccines (Basel) 2014;2:624-41.

142. Susanne R, Edith J, Kim S, Benjamin P. New vaccine technologies to Combat outbreak situations. Front Immunol 2018;9:1963.

143. Kobinger G, Fausther-Bovendo H. Pre-existing immunity against Ad vectors Humoral, cellular, and innate response, what's important? Hum Vaccines Immunother 2014;10: 2875-84.

144. Fcz A, Xhg B, Yhl C, Jyh D, Ptj E, Lhh F, et al. Immunogenicity and safety of a recombinant adenovirus type-5-vectored COVID-19 vaccine in healthy adults aged 18 years or older: a randomised, double-blind, placebo-controlled, phase 2 trial. The Lancet 2020;396:479-88.
145. Zhang YJ, Li YY, Wang L, Li MY, Zhou XH. Evaluating transmission heterogeneity and super-spreading event of COVID-19 in a Metropolis of China. Int J Environ Res Publ Health 2020;17:3705.

146. Zheng N, Ran X, Yang C, Yin B, Li Y, Duan C, et al. Boosted expression of the SARS-CoV nucleocapsid protein in tobacco and its immunogenicity in mice. Vaccine 2009;27: 5001-7.

147. Liu SJ, Leng CH, Lien SP, Chi HY, Huang CY, Lin CL, et al. Immunological characterizations of the nucleocapsid protein based SARS vaccine candidates. Vaccine 2006;24:3100-8.

148. Poland GA, Ovsyannikova IG, Crooke SN, Kennedy RB. SARS-CoV-2 vaccine development: current status. Mayo Clin Proc 2020;95:2172-88.

149. Smith TRF, Patel A, Ramos S, Broderick KE. Immunogenicity of a DNA vaccine candidate for COVID-19. Nat Commun 2020;11: 2601.

150. Graham BS, Mascola JR, Fauci AS. Novel vaccine technologies: essential components of an adequate response to emerging viral diseases. JAMA 2018;319:1431-2.

151. Pardi N, Hogan MJ, Porter FW, Weissman D. mRNA vaccines-a new era in vaccinology. Nat Rev Drug Discov 2018;17:261-79.

152. Anderson EJ, Rouphael NG, Widge AT, Jackson LA, Beigel JHJNEJM. Safety and immunogenicity of SARS-CoV-2 mRNA-1273 vaccine in older adults. N Engl J Med 2020;383:2427-38.

153. Moderna. Moderna's COVID-19 vaccine candidate meets its primary efficacy endpoint in the first interim analysis of the phase 3 COVE study. Moderna; 2020. https://www.biospace. com/article/releases/moderna-s-covid-19-vaccine-candidatemeets-its-primary-efficacy-endpoint-in-the-first-interimanalysis-of-the-phase-3-cove-study/ [Accessed 1 Dec 2021].

154. Mahase E. Covid-19: how many variants are there, and what do we know about them? BMJ Clin Res Ed 2021;374:n1971.

155. Thomas SJ, Edson D, Moreira J, Kitchin N, Absalon J, Gurtman A, et al. Safety and efficacy of the BNT162b2 mRNA COVID-19 vaccine through 6 months. N Engl J Med 2021;385: 1761-73.

156. Sheikh A, Mcmenamin J, Taylor B, Robertson C. SARS-CoV-2 Delta VOC in Scotland: demographics, risk of hospital admission, and vaccine effectiveness. The Lancet 2021;397: 2461-2.

157. Sahly HME, Baden LR, Essink B, Doblecki-Lewis S, Martin JM, Anderson EJ, et al. Efficacy of the mRNA-1273 SARS-CoV-2 vaccine at completion of blinded phase. N Engl J Med 2021;385: 1774-85.

158. Thompson MG, Burgess JL, Naleway AL, Tyner HL, Yoon SK, Meece J, et al. Interim estimates of vaccine effectiveness of BNT162b2 and mRNA-1273 COVID-19 vaccines in preventing SARS-CoV-2 infection among health Care personnel, first responders, and other essential and Frontline workers-eight U.S. Locations, December 2020-March 2021. MMWR Morb Mortal Wkly Rep 2021;70:495-500.

159. Falsey AR, Sobieszczyk ME, Hirsch I, Sproule S, Robb ML, Corey L, et al. Phase 3 safety and efficacy of AZD1222 (ChAdOx1 nCoV-19) covid-19 vaccine. N Engl J Med 2021;385:2348-60.

160. DailyMed. JANSSEN COVID-19 VACCINE- ad26.cov2.s injection, suspension. U.S. National Institutes of Health; 2021. Updated 22 Nov 2021. Available from: https://dailymed.nlm.nih.gov/ dailymed/drugInfo.cfm?setid=14a822ff-f353-49f9-a7f221424b201e3b [Accessed 4 Dec 2021]. 
161. Al Kaabi N, Zhang Y, Xia S, Yang Y, Al Qahtani MM, Abdulrazzaq $\mathrm{N}$, et al. Effect of 2 inactivated SARS-CoV-2 vaccines on symptomatic COVID-19 infection in adults: a randomized clinical trial. JAMA 2021;326:35-45.

162. Tanriover M, Doanay HL, Akova M, Güner H, Aksu K. Efficacy and safety of an inactivated whole-virion SARS-CoV-2 vaccine (CoronaVac): interim results of a double-blind, randomised, placebo-controlled, phase 3 trial in Turkey. The Lancet 2021; 398:213-22.

163. Ella R, Reddy S, Blackwelder W, Potdar V, Yadav P, Sarangi V, et al. Efficacy, safety, and lot-to-lot immunogenicity of an inactivated SARS-CoV-2 vaccine (BBV152): interim results of a randomised, double-blind, controlled, phase 3 trial. The Lancet 2021;398: 2173-84.

164. WHO. Fair allocation mechanism for COVID-19 vaccines through the COVAX Facility; 2020. Available from: https://www.who.int/ publications $/ \mathrm{m} /$ item/fair-allocation-mechanism-for-covid19-vaccines-through-the-covax-facility [Accessed 8 Aug 2021].

165. Wouters OJ, Shadlen KC, Salcher-Konrad M, Pollard AJ, Larson $\mathrm{HJ}$, Teerawattananon $\mathrm{Y}$, et al. Challenges in ensuring global access to COVID-19 vaccines: production, affordability, allocation, and deployment. Lancet (London, England) 2021; 397:1023-34.

166. WHO. COVAX announces additional deals to access promising COVID-19 vaccine candidates; plans global rollout starting Q1; 2021. Updated 2021. Available from: https://www.who.int/ news/item/18-12-2020-covax-announces-additional-deals-toaccess-promising-covid-19-vaccine-candidates-plans-globalrollout-starting-q1-2021 [Accessed 16 Aug 2021].

167. Emanuel EJ, Luna F, Schaefer GO, Tan K-C, Wolff J. Enhancing the WHO's proposed framework for distributing COVID-19 vaccines among countries. Am J Publ Health 2021;111:371-3.

168. Herzog LM, Norheim OF, Emanuel EJ, McCoy MS. Covax must go beyond proportional allocation of covid vaccines to ensure fair and equitable access. BMJ Clin Res Ed 2021;372: m4853.

169. WHO. WHO SAGE values framework for the allocation and prioritization of COVID-19 vaccination; 2020. Available from: https://www.who.int/publications/i/item/who-sage-valuesframework-for-the-allocation-and-prioritization-of-covid19-vaccination [Accessed 17 Aug 2021].
170. Hale T, Angrist N, Goldszmidt R, Kira B, Petherick A, Phillips T, et al. A global panel database of pandemic policies (Oxford COVID-19 Government Response Tracker). Nat Hum Behav 2021; 5:529-38.

171. Smith DD, Pippen JL, Adesomo AA, Rood KM, Landon MB, Costantine MM. Exclusion of pregnant women from clinical trials during the coronavirus disease 2019 pandemic: a review of international registries. Am J Perinatol 2020;37:792-9.

172. Beigi RH, Krubiner C, Jamieson DJ, Lyerly AD, Hughes B, Riley L, et al. The need for inclusion of pregnant women in COVID-19 vaccine trials. Vaccine 2021;39:868-70.

173. D P, N-S K, MS A, B D. COVID-19 vaccines and neglected pregnancy. Lancet 2020;396:e22.

174. Maykin MM, Heuser C, Feltovich H. Pregnant people deserve the protection offered by SARS-CoV-2 vaccines. Vaccine 2021;39: 171-2.

175. Krubiner CB, Faden RR, Karron RA, Little MO, Lyerly AD, Abramson JS, et al. Pregnant women \& vaccines against emerging epidemic threats: Ethics guidance for preparedness, research, and response. Vaccine 2021;39:85-120.

176. Male V. Are COVID-19 vaccines safe in pregnancy? Nat Rev Immunol 2021;21:200-1.

177. Shimabukuro TT, Kim SY, Myers TR, Moro PL, Oduyebo T, Panagiotakopoulos $L$, et al. Preliminary findings of mRNA covid19 vaccine safety in pregnant persons. N Engl J Med 2021;384: 2273-82.

178. Ndugga NHL, Artiga S, Parker N. atest data on COVID-19 vaccinations by race/ethnicity. KFF; 2021. Updated 2021. Available from: https://www.kff.org/coronavirus-covid-19/ issue-brief/latest-data-on-covid-19-vaccinations-raceethnicity/ [Accessed 21 Aug 2021].

179. Criss S, Nguyen TT, Norton S, Virani I, Titherington E, Tillmanns EL, et al. Advocacy, hesitancy, and equity: exploring U.S. Racerelated discussions of the COVID-19 vaccine on Twitter. Int J Environ Res Public Health 2021;18:5693.

180. The Lancet Infectious Diseases. COVID-19 vaccine equity and booster doses. Lancet Infect Dis 2021;21:1193.

Supplementary material: The online version of this article offers supplementary material (https://doi.org/10.1515/mr-2021-0023). 